\title{
The formation of SOA and chemical tracer compounds from the photooxidation of naphthalene and its methyl analogs in the presence and absence of nitrogen oxides
}

\author{
T. E. Kleindienst ${ }^{1}$, M. Jaoui ${ }^{2}$, M. Lewandowski ${ }^{1}$, J. H. Offenberg ${ }^{1}$, and K. S. Docherty ${ }^{2}$ \\ ${ }^{1}$ National Exposure Research Laboratory, U.S. Environmental Protection Agency, Research Triangle Park, \\ North Carolina 27711, USA \\ ${ }^{2}$ Alion Science and Technology, P.O. Box 12313, Research Triangle Park, North Carolina 27709, USA \\ Correspondence to: T. E. Kleindienst (kleindienst.tad@epa.gov)
}

Received: 14 March 2012 - Published in Atmos. Chem. Phys. Discuss.: 11 May 2012

Revised: 5 September 2012 - Accepted: 6 September 2012 - Published: 27 September 2012

\begin{abstract}
Laboratory smog chamber experiments have been carried out to investigate secondary organic aerosol (SOA) formation from the photooxidation of naphthalene and its methyl analogs, 1- and 2-methylnaphthalene (1-MN and 2$\mathrm{MN}$, respectively). Laboratory smog chamber irradiations were conducted in a flow mode to ensure adequate collection of the aerosol at reasonably low reactant concentrations and in the presence and absence of nitrogen oxides. Phthalic acid and methyl analogs were identified following BSTFA derivatization of the aerosol extract. These compounds were examined to determine whether they could serve as reasonable molecular tracers to estimate the contributions of these precursors to ambient $\mathrm{PM}_{2.5}$. Measurements were also made to determine aerosol parameters from secondary organic aerosol from naphthalene, 1-MN, and 2-MN.

A mass fraction approach was used to establish factors which could be applied to phthalic acid concentrations in ambient aerosols, assuming a negligible contribution from primary sources. Phthalic anhydride uptake (and hydrolysis) was tested and found to represent a moderate filter artifact in filter measurements with and without in-line denuders. This study provided the opportunity to examine differences using authentic standards for phthalic acid compared to surrogate standards. While the mass fraction based on a surrogate compounds was somewhat lower, the differences are largely unimportant. For naphthalene, mass fractions of 0.0199 (recommended for ambient samples) and 0.0206 were determined in the presence and absence of nitrogen oxides, respectively, based on phthalic acid standards.
\end{abstract}

The mass fractions determined from the laboratory data were applied to ambient samples where phthalic acid was found and expressed "as naphthalene" since phthalic acid was found to be produced in the particle phase from other methylnaphthalenes. The mass fraction values were applied to samples taken during the 2005 SOAR Study in Riverside, CA and 2010 CalNex Study in Pasadena. In both studies an undetermined isomer of methylphthalic acid was detected in addition to phthalic acid. Laboratory experiment retention times and mass spectra suggest that the major precursor for this compound is 2-MN. For the CalNex Study, SOC values for the 2-ring precursor PAHs (as naphthalene) were found to range from below the detection limit to $20 \mathrm{ngC} \mathrm{m}^{-3}$ which with the laboratory mass fraction data suggests an upper limit of approximately $1 \mu \mathrm{g} \mathrm{m}^{-3}$ for SOA due to 2-ring PAHs. Temporal data over the course of the one-month CalNex study suggest that primary sources of phthalic acid were probably negligible during this study period. However, the values must still be considered upper limits given a potential hydrolysis reaction or uptake of phthalic anhydride (subsequently hydrolyzed) onto the collection media.

\section{Introduction}

$\mathrm{PM}_{2.5}$ is composed of a wide variety of organic and inorganic components of primary and secondary origin. A review of the literature shows that the inorganic composition of ambient $\mathrm{PM}_{2.5}$ is reasonably well established and the sources 
have been identified. However, while numerous organic compounds have been identified in field studies (e.g., Pio et al., 2001), the fraction of identified organic species in ambient $\mathrm{PM}_{2.5}$ samples remains low, complicating efforts to identify primary and secondary organic sources. Organic tracer-based source apportionment methods have been employed to determine the contributions of specific primary organic sources to ambient organic carbon concentrations (Schauer et al., 1996). The determination of secondary sources of organic aerosol in $\mathrm{PM}_{2.5}$ remains problematic.

Recent studies have identified organic compounds found in $\mathrm{PM}_{2.5}$ with identical tracer compounds produced in laboratory irradiations of isoprene (Edney et al., 2005), monoterpenes (Jaoui et al., 2005; Claeys et al., 2007; Szmigielski et al., 2007), sesquiterpenes (Jaoui et al., 2007), and aromatic hydrocarbons (Kleindienst et al., 2004). These findings have led to the development of an organic tracer-based method (Kleindienst et al., 2007) for apportioning secondary organic carbon (SOC) from the mass fraction of the identified tracer compounds to SOA formed from single-component laboratory irradiations of each hydrocarbon (HC) given above. The method appeared to give a reasonable apportioning of secondary precursors in the eastern United States where biogenic hydrocarbons have been found to be the major summertime precursors for SOA (Lewandowski et al., 2008).

Recent work has indicated that this approach, and similar methods, might not be sufficient to help understand SOA formation in areas with strong anthropogenic influences (deGouw et al., 2005). A classic view of SOA formation has been based on the generation of secondary aerosol products from aromatic hydrocarbons and monoterpenes by an absorptive gas-particle partitioning mechanism (Odum et al., 1996). This approach to SOA formation has the advantage that model parameters can be generated readily from laboratory experiments to provide an experimental basis for SOA formation yields, which can then be used to predict SOA formation in an air quality model.

Limitations of the classic SOA model, however, have become apparent as a result of comparisons with field measurements (Pun et al., 2003). Other possible volatile organic compound (VOC) precursors not considered in the classic partitioning method (SOA from aromatic hydrocarbons and monoterpenes) may contribute to ambient SOA. For some precursors that potentially have high SOA yields (e.g., sesquiterpenes, polyaromatic hydrocarbons (PAHs)), it is also difficult to predict SOA contributions given uncertainties in the emission rates. Heterogeneous processes also are not considered in the classic SOA model (Hallquist et al., 2009).

Field data have also shown the limitations of the classic model for SOA formation in real atmospheres. During the 2002 New England Air Quality Study, deGouw et al. (2005) found that the composition of submicron particulate organic matter (POM) was highly dependent on the atmospheric processing. Measurements over a two-day period, which fol- lowed emissions from east coast US cities, showed correlations between POM and isopropyl nitrate, suggesting anthropogenic precursors for POM. Further measurements by deGouw et al. (2008) during the 2004 ICARTT study again indicated the source of POM was unexplained anthropogenic sources, although more than one-third of the POM could be explained as processed emissions of aromatic hydrocarbons.

Unexplained ambient aerosol generally has been found to be highly oxygenated and cannot be reconciled by known biogenic sources. Heald et al. (2005) found that levels of organic carbon (OC) in the free troposphere (a.s.1.: 2-6.5 km) had average carbon levels of $4 \mu \mathrm{g} \mathrm{m}^{-3}$, which were between 10 and 100 times higher than that predicted using GEOSChem with a conventional SOA formation mechanism, that is, the two-product model. Robinson et al. (2007) found that the precursors giving rise to unexplained POM could come from moderate to high molecular weight hydrocarbons produced in diesel combustion processes. Gas-phase precursors were expected to result from the particle-gas phase partitioning upon dilution of the exhaust, which could then react and recondense onto preexisting particulate matter following oxidation in the atmosphere. However, these emissions formed upon dilution are not readily quantifiable using standard analytical techniques and typically are not included in emission inventories. Accompanying experimental data indicated that these emissions could be efficient producers of SOA even in the presence of nitric oxide. These findings are consistent with those of Volkamer et al. (2007), who determined during the MILAGRO Study in Mexico City that even first-generation products of relatively small molecules such as glyoxal can be efficient producers of SOA during early stages of photooxidation.

Such studies suggest that anthropogenic hydrocarbons, such as gas-phase PAHs, could be playing a role in producing measurable SOA. Naphthalene and its methyl-substituted analogs are by far the most volatile 2-ring PAHs, and they are readily detected in diesel exhaust (Schauer et al., 1999). Naphthalene concentrations in urban atmospheres have been reported as high as $1600 \mathrm{ng} \mathrm{m}^{-3}$ in Los Angeles (Reisen and Arey, 2005). Similar to the reactions of $\mathrm{OH}+$ aromatic hydrocarbons, its dominant loss mechanism is ring cleavage that leads to dicarbonyl products in the gas phase and other ring-retaining coproducts. Subsequent reactions of the primary products has been found to generate phthalic anhydride (Wang et al., 2007), which possibly hydrolyzes heterogeneously to form phthalic acid (PhA). Detection of PhA in ambient $\mathrm{PM}_{2.5}$ has been broadly reported (e.g., Fraser et al., 2003).

Particle-phase compounds from the photooxidation of naphthalene have been explored to determine the extent to which $\mathrm{PhA}$ is formed, with the intent of possibly using it as a tracer compound in ambient samples. Up until now, PhA has been considered mainly in terms of its correlation with SOA in ambient samples (Schauer et al., 2002; Fraser et al., 2003; Fine et al., 2004). While PhA has been detected in laboratory 
and field samples, no attempt has been made to use it to estimate the contribution of two-ring precursor compounds to measured SOA. Moreover, the possibility of primary sources of $\mathrm{PhA}$, such as from plasticizers, could diminish the value of such a tracer in air sheds where source information is missing (Kautzman et al., 2010). These authors have suggested that other compounds detected in ambient and laboratory samples (e.g., 4-nitro-1-naphthol) could be used as tracer compounds because they are unlikely to be found from primary aerosol sources. However, approaches using liquid chromatography to estimate tracer concentrations in atmospheric samples are highly dependent on availability of authentic standards limiting its use in source attribution applications. Thus, the research conducted to date has provided only aerosol parameterization to be used in air quality models.

The present work examines tracer compounds generated from the photooxidation of naphthalene and 1- and 2methylnaphthalene (1-MN and 2-MN) in the presence and absence of oxides of nitrogen $\left(\mathrm{NO}_{\mathrm{x}}\right)$. The SOA mass fraction approach used follows closely that described by Kleindienst et al. (2007) in which smog chamber irradiations are conducted of a single component hydrocarbon precursor in air mixtures, which photolytically generates hydroxyl radicals $(\mathrm{OH})$. The laboratory-determined mass fraction of the tracer compound to the measured SOA (or SOC) is then applied to ambient $\mathrm{PM}_{2.5}$ samples to estimate the contribution of precursor hydrocarbon. For many of the experiments conducted for tracer analysis, measurements were also obtained for the organic mass to organic carbon ratios (OM/OC), organic aerosol yields, and the apparent volatility of the composite aerosol.

\section{Experimental methods}

Most of the laboratory and field measurement methods have been described previously (Kleindienst et al., 2007, 2009). Experiments to measure SOA and associated tracer compounds formed from naphthalene, 1-MN, and 2-MN were carried out in a $14.5 \mathrm{~m}^{3}$ stainless-steel chamber with walls coated with TFE Teflon. For the laboratory experiments in this work, the chamber was operated as a continuous stirred tank reactor (CSTR), that is, as a flow-mode reactor (also known as a dynamic-mode reactor). In this mode, reactants were added to a manifold using mass flow controllers while the effluent obtained for analysis was withdrawn continuously. The average residence time in the chamber was $5.1 \mathrm{~h}$, and the reaction mixture was brought to steady-state before sampling began. The photolytic system had four banks of 40 fluorescent bulbs consisting of a combination of UVA340 bulbs (Q-Panel, Cleveland, $\mathrm{OH}$ ) and standard UV bulbs (GE F40-BL), which provided nearly complete actinic coverage. For experiments requiring the photolysis of $\mathrm{H}_{2} \mathrm{O}_{2}$, UVsunlamps (UV-313) were added to the irradiation system to increase the intensity of the radiation from 280 to $320 \mathrm{~nm}$ (Kleindienst et al., 2009).

The reactant generation system provided constant sources of zero air, gas-phase reactants, water vapor, and seed aerosol. The seed aerosol was generated by nebulizing a $10 \mathrm{mg}^{-1}$ aqueous solution of ammonium sulfate. Nitric oxide (NO) was obtained from a high-pressure cylinder of $1 \%$ $\mathrm{NO}$ in $\mathrm{N}_{2}$. Naphthalene and the methylnaphthalenes were purchased from Aldrich Chemical Co. (Milwaukee, WI) at the highest purity available and used without further purification. All solvents were obtained from Burdick and Jackson (Muskegon, MI) and specified as $\mathrm{GC}^{2}$ quality. BSTFA reagent (with $1 \%$ trimethylchlorosilane) used for $\mathrm{OH}$ derivatization was also obtained from Aldrich Chemical Co.

Hydrocarbon reactants were added by two different means. 1-MN, which is a liquid at room temperature, was vaporized by passing air through the thermostated liquid in an impinger. For naphthalene and 2-MN, which are solids at room temperature, air was passed over the pure compound to sweep the sublimated vapor into the chamber in a controlled fashion. Heated lines obviated the likelihood of reactant condensation in the transfer lines. A relative humidity (RH) generator with a computer-controlled peristaltic pump and hightemperature vaporizer was used to add water vapor precisely to the chamber for experiments where $\mathrm{NO}_{\mathrm{x}}$ was injected as a reactant. The chamber was operated at $25^{\circ} \mathrm{C}$ during the experiments.

Hydroxyl radicals $(\mathrm{OH})$ initiated the oxidation of the hydrocarbon reactants. For experiments with oxides of nitrogen $\left(\mathrm{NO}_{\mathrm{x}}\right)$ present, $\mathrm{OH}$ was produced from the photolysis of methyl nitrite or by the conventional chain-propagating mechanism, which generates $\mathrm{OH}$ via the reaction of $\mathrm{NO}$ with $\mathrm{HO}_{2}$. In experiments with $\mathrm{NO}_{\mathrm{x}}$, the chamber was operated at $30 \%$ RH. For experiments without $\mathrm{NO}_{\mathrm{x}}, \mathrm{OH}$ was generated from the photolysis of hydrogen peroxide $\left(\mathrm{H}_{2} \mathrm{O}_{2}\right)$ with the chamber operated without added water vapor $(\mathrm{RH}<3 \%)$.

Compounds added or generated in the chamber were measured using a variety of analytical methods. Oxides of nitrogen were measured using a Monitor Labs, Inc. Model 8840 oxides of nitrogen chemiluminescence analyzer. Hydrocarbon reactant concentrations were measured by gas chromatography-flame ionization detection (GC-FID) with a double focusing cryogenic system. These samples were collected in a sampling loop held at $-180^{\circ} \mathrm{C}$ and then flash heated to $260^{\circ} \mathrm{C}$ to inject the analytes onto the head of the GC column. A semi continuous GC system (HP 5890, Hewlett Packard, Palo Alto, CA) was also used to measure organic compounds in the chamber and inlet manifold on a 20-min duty cycle. Temperature and RH were measured using a digital thermo hygrometer (Model RH411, Omega Engineering, Inc., Stamford, CT).

Aerosol chemical and physical properties were measured using a variety of continuous and integrated methods. Organic carbon concentrations were measured using an automated, semicontinuous elemental carbon-organic carbon 
(EC-OC) instrument (Sunset Laboratories; Tigard, OR). Since elemental carbon was not present in these systems, the measured total carbon was equivalent to SOC. The instrument operated at a flow rate of $81 \mathrm{~min}^{-1}$ with a sample collection time of $30 \mathrm{~min}$. The analysis was conducted using a thermooptical analytical technique (Birch and Cary, 1996) with the instrument operated on a 45 -min duty cycle. In addition to SOC, the OM concentration (numerically equivalent to the chamber SOA) was determined by gravimetric analysis of a filter sample collection. The OM masses were corrected by subtracting the seed aerosol mass of $1 \mu \mathrm{g} \mathrm{m}{ }^{-3}$.

The volatility of the photochemically produced organic aerosol was determined using the volatility differential mobility analysis (VDMA) technique, which uses a size mobility particle scanner (SMPS) to measure the volume distribution of the chamber aerosol (Offenberg et al., 2006). This volatility parameter, $\Delta H_{\text {vap }}^{\text {eff }}$, is used in this context simply as an operational parameter to represent the change in the volatility of composite aerosol as a function of temperature. Unlike techniques that use tandem differential mobility analyzers (DMAs), this method uses a $25-\mathrm{cm}$ heated line coupled to the inlet to measure the integrated volume over the entire SMPS size range (18-931 nm). The technique is feasible because the aerosol volume remains constant over the course of the irradiation at steady state. The use of the technique is identical to that described in earlier publications (e.g., Kleindienst et al., 2009).

Individual organic compounds in the particle phase were determined using gas chromatography-mass spectroscopy (GC-MS) analysis of filter samples. For consistency with previous measurements, aerosol measurements from laboratory samples were made using Teflon-impregnated, glassfiber (TIGF) filters, whereas field sample measurements were made using quartz filters, which could be prone to gas-phase uptake of organic compounds. Thus, to evaluate the possible effect of gas-phase phthalic anhydride on the filter results, Experiment ER579 (Table 1) used a sampling train that consisted of organic denuders followed by $47-\mathrm{mm}$ TIGF or quartz filters. In an additional configuration, an extractable denuder was used containing eight concentric glass tubes coated with the XAD-4 solid phase adsorbent (Gundel et al., 1995). Experiment ER579 also consisted of comparing sideby-side TGIF and quartz filters. Further details regarding these sampling configurations and denuder extract analysis are given by Kleindienst et al. (2004, 2009). For the present experiment, it should be noted that the analysis measures phthalic acid, whereas the putative interfering compound subject to uptake is phthalic anhydride.

Individual organic compounds from the denuder or the chamber aerosol were determined by derivatization with N,O-bis(trimethylsilyl) trifluoroacetamide (BSTFA; Jaoui et al., 2004). Reactions of BSTFA with hydroxylated groups form a trimethyl silyl (TMS) derivative which improves the chromatography of tracer peaks that might otherwise tail considerably. Laboratory filter samples were Soxhlet- extracted with dichloromethane for $6 \mathrm{~h}$ or sonicated in 1 : $1(v / v)$ dichloromethane/methanol mixture for $1 \mathrm{~h}$. Prior to the extraction, $20 \mu \mathrm{g}$ each of cis-ketopinic acid (KPA) and $d_{50}$-tetracosane were added as internal standards. Extracts were dried and then derivatized with $250 \mu$ of BSTFA with $1 \%$ TMCS as a catalyst and $100 \mu \mathrm{l}$ of pyridine. Samples were heated to complete the derivatization reaction and then injected onto the GC without a further reduction in volume. Filters from the field samples were extracted by Soxhlet extraction for $24 \mathrm{~h}$ using $125 \mathrm{ml}$ of a $1: 1(v / v)$ dichloromethane/methanol mixture. Prior to the extraction, cis-ketopinic acid and tetracosane- $d_{50}$ were added as internal and recovery standards, respectively. Filter extracts were rotary evaporated to $1 \mathrm{ml}$ and then evaporated to dryness with ultrazero nitrogen.

Each derivatized extract for both laboratory and field samples were analyzed by GC-ion trap mass spectrometer (GCITMS; Thermoquest Model GCQ+, Austin, TX). Samples were injected into the heated inlet and separated using an $\mathrm{RT}_{\mathrm{x}}-5 \mathrm{MS}$ column $(60-\mathrm{m}$ length $\times 0.25$-mm i.d. $\times 0.25$ $\mu \mathrm{m}$ film thickness; Restek, Inc., Bellefonte, PA). GC operating conditions were identical to those described previously (Kleindienst et al., 2010a). Sample detection and analysis was conducted in either the positive electron ionization (EI) or chemical ionization (CI) modes with methane as the reagent gas over a $\mathrm{m} / z$ range between 70 and $975 \mathrm{Da}$. Using the EI mode is feasible for this tracer compound since standards are readily available or can be easily produced in the laboratory. Here, the calibrations for the laboratory experiments have been based on external PhA standards and only the CI data are presented. For the field samples, the tracers were typically analyzed from the total ion chromatogram (TIC) or, in cases where co-elutions occurred, by a selected ion technique using five molecular ions as previously described (Kleindienst et al., 2007). The use of the five-ion-toTIC calibration factor tend to provide more consistent concentration estimates than those from a single ion. TIC areas were then used to determine the SOA tracer concentrations in $\mathrm{ng} \mathrm{m}^{-3}$. For PhA, the five ions used were $m / z$ 295, 221, 311, 339 , and 351 corresponding to the respective fragments and adducts of (M-15), (M-89), (M+1), $(\mathrm{M}+29)$, and $(\mathrm{M}+41)$. In addition, methyl phthalic acid (MPhA; see below) was also detected in the laboratory samples from aerosol produced in the 1-MN and 2-MN photooxidation and in selected cases in field sample extracts. For 2MPhA-2, the only MPhA isomer detected in field samples, the five ions used were $m / z$ 309, $235,325,351$, and 365 corresponding to the respective fragments and adducts indicated above.

Results from two field studies are also included which apply the laboratory findings to ambient tracer data. The first set was taken during the 2005 Study of Organic Aerosols in Riverside (SOAR-1; Docherty et al., 2008). In the sampling scheme for the filter collection, aerosol was composited for multiple days over identical times periods (05:0010:00; 10:00-15:00; 15:00-20:00; and 20:00-05:00; PDT) 
Table 1. Initial conditions for experiments producing SOA from naphthalene photooxidations. The experiments were conducted with chamber operated in a dynamic (i.e., flow) mode, except for ER457 and ER458 which were conducted in a batch mode. All experiments with $\mathrm{NO}_{\mathrm{x}}$ were conducted at a relative humidity of $30 \%$ and no water vapor was added to experiments without $\mathrm{NO}_{\mathrm{x}}(\mathrm{RH}<3 \%)$.

\begin{tabular}{llllll}
\hline Expt No. $^{\mathrm{a}}$ & Purpose & $\mathrm{HC}(\mathrm{ppmC})$ & $\mathrm{CH}_{3} \mathrm{ONO}(\mathrm{ppm})$ & $\mathrm{NO}(\mathrm{ppm})$ & $\mathrm{H}_{2} \mathrm{O}_{2}(\mathrm{ppm})$ \\
\hline ER457 & Tracer & 0.75 & 0.191 & 0.606 & - \\
ER458 & Tracer & 1.95 & 0.163 & 0.599 & - \\
ER459-1 & Tracer, Parameter & 1.01 & 0.136 & 0.303 & - \\
ER459-2 & Tracer, Parameter & 1.01 & 0.136 & 0.152 & - \\
ER512 & Tracer, Parameter & 2.35 & - & $0.295^{\mathrm{b}}$ & - \\
ER539 & Parameter & 1.74 & - & $0.260^{\mathrm{b}}$ & - \\
ER579 & Parameter, putative phthalic anhydride uptake & 0.97 & - & $0.242^{\mathrm{b}}$ & - \\
ER460-1 $a$ & Tracer & 1.03 & - & - & 4.4 \\
ER460-1 $b$ & Tracer, Parameter & 1.03 & - & - & 4.1 \\
ER460-2 & Tracer, Parameter & 1.03 & - & - & 2.1 \\
ER461-1 $a$ & Tracer, Parameter & 0.24 & - & - & 4.4 \\
ER461-1 $b$ & Tracer & 0.24 & - & - & 4.4 \\
\hline
\end{tabular}

a Parts $a$ and $b$ represent parallel filters from the same experiment;

${ }^{b}$ Initial $\left[\mathrm{NO}_{\mathrm{X}}\right]$ equivalent to [NO].

for weekend and weekday periods. In a second study, filter samples were taken during the 2010 California Research at the Nexus of Air Quality and Climate Change (CalNex) Study. Daily filter samples were collected over 23-h periods from midnight to 11:00 p.m. (PDT) from 15 May-15 June 2010. Additional information on the CalNex study can be found, for example, in Washenfelder et al. (2011).

\section{Results}

Irradiations were conducted using naphthalene, 1-MN, and 2-MN as hydrocarbon reactants and $\mathrm{OH}$ as the oxidant in the presence and absence of $\mathrm{NO}_{\mathrm{x}}$. For most experiments in the presence of $\mathrm{NO}_{\mathrm{x}}, \mathrm{OH}$ radicals were produced initially through the photolysis of methyl nitrite. While methyl nitrite is not strictly essential since the naphthalene reacts rapidly with $\mathrm{OH}$, the chain propagating processes in its $\mathrm{NO}_{\mathrm{x}}$ irradiations are not robust due to organic chain terminating processes, and thus the addition of methyl nitrite helps to ensure that the extent of reaction is sufficiently high to produce a highly oxidized aerosol. For experiments in the absence of $\mathrm{NO}_{\mathrm{x}}, \mathrm{OH}$ radicals were generated from the photolysis of hydrogen peroxide. Initial naphthalene concentrations ranged from 0.2-2.4 ppmC (20-240 ppb). For respective experiments in the absence and presence of $\mathrm{NO}_{\mathrm{x}}, \mathrm{NO}_{\mathrm{y}}$ (which includes $\mathrm{CH}_{3} \mathrm{ONO}$ ) values from $0.2-0.8 \mathrm{ppm}$ and $\mathrm{H}_{2} \mathrm{O}_{2}$ values from 2-4 ppm were used. The exact initial conditions for the experiments are given in Table 1. A more limited number of experiments were performed with the two monomethyl naphthalene isomers. However, for both methyl analogs, experiments were also performed in the presence and absence of $\mathrm{NO}_{\mathrm{x}}$ with initial conditions provided in Table 2.
Steady-state chamber concentrations of the reacted naphthalene, $\mathrm{NO}_{\mathrm{y}}$, and $\mathrm{O}_{3}$, where applicable, are given in the upper portion of Table 3. For experiments without $\mathrm{NO}_{\mathrm{x}}$, the photolysis of $\mathrm{H}_{2} \mathrm{O}_{2}$ was the only source of $\mathrm{OH}$, since $\mathrm{OH}$ cannot be generated by catalytic means in these types of photochemical systems not involving $\mathrm{NO}_{\mathrm{x}}$. The reacted naphthalene is determined from the difference of the initial and steady-state naphthalene concentrations. For these experiments, the reacted naphthalene concentration range was $0.24-0.86 \mathrm{ppmC}$. The random uncertainty in the reacted naphthalene and methyl naphthalenes result from the reproducibility of both the initial and steady-state hydrocarbons values by gas chromatography and is estimated to range between 30 and $50 \%$ due to the relatively low volatility of these compounds.

Also shown in Table 3 are steady-state chamber concentrations for five experiments with $\mathrm{NO}_{\mathrm{x}}$ present in the reactant mixture. Even in the cases with $\mathrm{CH}_{3} \mathrm{ONO}$ being used to generate $\mathrm{OH}$ initially, a modest fraction of the $\mathrm{NO}$ initially present $(0.03-0.33)$ remained under steady-state conditions. Substantial levels of $\mathrm{NO}_{\mathrm{x}}$ but relatively little ozone were also produced at steady state as seen in Table 3 . Given the modest steady-state concentrations of $\mathrm{NO}$, it is unlikely under these conditions that peroxy-peroxy radical $\left(\mathrm{RO}_{2}-\mathrm{HO}_{2}\right.$ and $\mathrm{RO}_{2}-$ $\mathrm{RO}_{2}$ ) reactions were occurring substantially, and thus SOA formation observed were due to reactions occurring in the presence of NO.

With the chamber operated in a steady-state mode, a constant aerosol source was maintained for initial conditions given in Tables 1 and 2. The major aerosol parameters measured, including SOA and SOC, are given in Table 3. Uncertainties in the SOC values are taken from the reproducibility of the semicontinuous measurement and are typically better than $10 \%$ for a single run, although this does not include 
Table 2. Initial conditions for laboratory irradiations of 1- and 2-methylnaphthalenes. The experiments were conducted with chamber operated in a dynamic (i.e., flow) mode.

\begin{tabular}{llllll}
\hline Expt No. & $\mathrm{HC}$ & Purpose & $\mathrm{C}_{11} \mathrm{H}_{10}(\mathrm{ppmC})$ & $\mathrm{NO}(\mathrm{ppm})$ & $\mathrm{H}_{2} \mathrm{O}_{2}(\mathrm{ppm})$ \\
\hline ER-467 & 1-MN & Parameter, Tracer & 0.763 & - & 4 \\
ER-470 & 1-MN & Parameter, Tracer & 0.821 & 0.180 & - \\
ER-468 & 2-MN & Parameter, Tracer & 1.01 & - & 4 \\
ER-469-1 & 2-MN & Parameter, Tracer & 0.944 & 0.299 & - \\
ER-469-2 & 2-MN & Parameter, Tracer & 0.944 & 0.186 & - \\
\hline
\end{tabular}

Table 3. Steady-state parameters determined from SOA produced by the naphthalene, 1-MN, and 2-MN laboratory photooxidations. The SOA and SOC yields, the OM/OC ratio, and $\Delta H_{\text {vap }}^{\text {eff }}$ were determined from the chamber concentrations. Reacted and formation values were corrected for chamber losses.

\begin{tabular}{|c|c|c|c|c|c|c|c|c|c|c|}
\hline & $\begin{array}{r}\text { Reacted HC } \\
(\text { ppmC) }\end{array}$ & $\begin{array}{r}\text { Reacted } \mathrm{HC}^{\mathrm{a}} \\
\quad\left(\mu \mathrm{g} \mathrm{m}^{-3}\right)\end{array}$ & $\begin{array}{r}\mathrm{NO}_{\mathrm{x}} \\
(\mathrm{ppm})\end{array}$ & $\begin{array}{r}\mathrm{O}_{3} \\
(\mathrm{ppm})\end{array}$ & $\begin{array}{r}\text { SOA } \\
\left(\mu \mathrm{g} \mathrm{m}^{-3}\right)\end{array}$ & $\begin{array}{r}\mathrm{SOC} \\
\left(\mu \mathrm{gC} \mathrm{m}^{-3}\right)\end{array}$ & $\mathrm{OM} / \mathrm{OC}$ & $\begin{array}{c}\Delta H_{\mathrm{vap}}^{\mathrm{eff}^{\mathrm{b}}} \\
\left(\mathrm{kJ} \mathrm{mol}^{-1}\right)\end{array}$ & $Y_{\mathrm{SOA}}$ & $Y_{\mathrm{SOC}}^{\mathrm{c}}$ \\
\hline \multicolumn{11}{|c|}{ Naphthalene } \\
\hline ER459-1 ${ }^{\mathrm{d}}$ & 0.72 & 375.0 & 0.281 & 0.007 & 100.3 & 46.9 & 2.14 & 15.1 & 0.27 & 0.13 \\
\hline ER459-2 & 0.79 & 409.7 & 0.111 & 0.045 & 118.3 & 60.3 & 1.96 & - & 0.29 & 0.16 \\
\hline ER512-1 & 1.44 & 749.4 & 0.232 & 0.012 & 132.2 & 59.3 & 2.23 & - & 0.18 & 0.08 \\
\hline ER512-2 & 1.49 & 775.2 & 0.254 & 0.002 & 82.6 & 40.3 & 2.05 & - & 0.11 & 0.06 \\
\hline ER539-1 & 0.64 & 333.2 & 0.201 & 0.013 & 84.7 & 49 & 1.73 & - & 0.25 & 0.16 \\
\hline ER539-2 & 0.65 & 339.7 & 0.195 & 0.013 & 89.2 & 53.6 & 1.66 & - & 0.26 & 0.17 \\
\hline ER539-3 & 0.64 & 332.6 & 0.190 & 0.015 & 94.2 & 54.1 & 1.74 & - & 0.28 & 0.17 \\
\hline ER579-1 & 0.54 & 281.2 & 0.220 & 0.002 & 38.9 & - & - & - & 0.14 & - \\
\hline ER579-2 & 0.59 & 306.0 & 0.215 & 0.002 & - & 22.9 & - & - & - & 0.08 \\
\hline $\mathrm{ER} 460-1^{\mathrm{e}}$ & 0.86 & 445.3 & - & - & 158 & 85.2 & 1.86 & 17.9 & 0.36 & 0.20 \\
\hline ER $460-2^{\mathrm{e}}$ & 0.82 & 427.6 & - & - & 131.7 & 71.0 & 1.86 & 19.3 & 0.31 & 0.18 \\
\hline ER461-1 ${ }^{\mathrm{e}}$ & 0.24 & 123.4 & - & - & 22.4 & 9.71 & 2.31 & 21.3 & 0.18 & 0.08 \\
\hline \multicolumn{11}{|l|}{$1-\mathrm{MN}$} \\
\hline $\mathrm{ER}-467^{\mathrm{e}}$ & 0.48 & 252.4 & - & - & 102.4 & 56.1 & 1.83 & 17.4 & 0.41 & 0.24 \\
\hline ER-470 & 0.41 & 213.1 & 0.130 & 0.005 & 42.8 & 16.1 & 2.66 & 15.7 & 0.20 & 0.08 \\
\hline \multicolumn{11}{|l|}{ 2-MN } \\
\hline $\mathrm{ER}-468^{\mathrm{e}}$ & 0.61 & 321.9 & - & - & 204.4 & 110 & 1.86 & 15.0 & 0.64 & 0.37 \\
\hline ER-469-1 & 0.51 & 267.3 & 0.265 & 0.002 & 36.9 & 10.4 & $3.45^{\mathrm{f}}$ & - & 0.13 & 0.04 \\
\hline ER-469-2 & 0.50 & 262.7 & 0.136 & 0.008 & 41.2 & 18.6 & 2.22 & 19.9 & 0.16 & 0.08 \\
\hline
\end{tabular}

${ }^{\text {a }}$ Reacted $\mathrm{HC}$ as carbon multiply values by 0.9325 .

b Measurements made over temperature range $50-250^{\circ} \mathrm{C}$.

${ }^{\mathrm{c}} Y_{\mathrm{SOC}}=\mathrm{SOC} / \triangle \mathrm{HC}_{\mathrm{C}}$.

${ }^{\mathrm{d}}$ Flow-mode experiments are represented by two part numbers where the first part (e.g., ER459) represents an individual experiment and the second part ( $-1,-2$, etc.) represents a distinct sampling period or change of conditions within the experiment.

e Measurements made without $\mathrm{NO}_{\mathrm{x}}$ present in the system.

${ }^{\mathrm{f}}$ Probably outlier due to low $Y_{\mathrm{SOC}}$.

possible systematic error. For OM, the uncertainties are determined from the reproducibility of side-by-side filter measurements which are typically better than $5 \%$. An estimate of the systematic errors due to minor changes in reactant concentrations, minor variations in chamber temperature, and other similar factors bring the total uncertainty to between 15 and $25 \%$ for these parameters. OM/OC values were then determined from the corrected data and given in Table 3. For experiments in the absence of $\mathrm{NO}_{\mathrm{x}}, \mathrm{OM} / \mathrm{OC}$ values ranged between 1.86 and 2.31 with an average value of 2.01. Similarly in the presence of $\mathrm{NO}_{\mathrm{x}}$, the measured values were between 1.66 and 2.33 with an average value of 1.93 . For 1-MN and 2-MN only single measurements were made for OM/OC which are found in Table 3 and exclude a likely outlier in Experiment ER-469-1.

From the organic aerosol produced in the naphthalene photooxidation in the absence and presence of $\mathrm{NO}_{\mathrm{x}}$, an effective enthalpy of vaporization was determined for the laboratory 
aerosol in selected experiments as described above. The values were obtained from the slope of a plot of $\ln V$ vs. $T^{-1}$ which when multiplied by the Gas Constant, $R$, gives a $\Delta H_{\text {vap }}^{\text {eff }}$. These values of $\Delta H_{\text {vap }}^{\text {eff }}$ are summarized in Table 3. For the experiments without $\mathrm{NO}_{\mathrm{x}}$ present, $\Delta H_{\text {vap }}^{\text {eff }}$ ranges between 21.3 and $17.9 \mathrm{~kJ} \mathrm{~mol}^{-1}$ with an average value $19.5 \mathrm{~kJ} \mathrm{~mol}^{-1}$. For the single experiments with $\mathrm{NO}_{\mathrm{x}}$ where $\Delta H_{\text {vap }}^{\text {eff }}$ was measure, a value of $15.1 \mathrm{~kJ} \mathrm{~mol}^{-1}$ was determined. These values are consistent with the ranges of values measured from aerosol generated in the photooxidation of alkylbenzenes (Offenberg et al., 2006).

The aerosol yield was determined for both organic mass and organic carbon. SOA masses were determined from the gravimetric mass formed during the irradiation. Organic carbon was determined by averaging the 30-min collections from the OC-EC instrument over the same period of time that the gravimetric mass was collected on filters. Similarly, the reacted hydrocarbon was obtained from the difference between the input concentration and the steady-state concentration over the same time period during the irradiations. For experiments using a flow mode reactor, the SOC yield $\left(Y_{\mathrm{SOC}}\right)$ and the SOA $\left(Y_{\mathrm{SOA}}\right)$ are determined from the following respective relationships:

$Y_{\mathrm{SOC}}=\mathrm{SOC} / \Delta \mathrm{HC}_{\mathrm{C}}$

$Y_{\mathrm{SOA}}=\mathrm{SOA} / \Delta \mathrm{HC}$

where SOC is the organic carbon concentration and $\Delta \mathrm{HC}_{\mathrm{C}}$ is the reacted naphthalene carbon (determined by multiplying $\triangle \mathrm{HC}$ by 0.9375$)$. SOA and SOC were also corrected for wall loss to the chamber which had previously been determined for organic aerosol to be $0.067 \mathrm{~h}^{-1}$. Uncertainties in the yield come from the combination of experimental uncertainties in the SOC and SOA values and the reacted naphthalene concentrations discussed earlier.

Yields for the experiments conducted in either the presence or absence of $\mathrm{NO}_{\mathrm{x}}$ are found in Table 3. For naphthalene, most of the measurements were made in experiments with $\mathrm{NO}_{\mathrm{x}}$ and show values within approximately a factor of two regardless of the organic mass present. Other factors, including the total $\mathrm{NO}_{\mathrm{x}}$ present in the system at steadystate, as well as the presence of methyl nitrite in the system, did not help in explaining the results. Thus, the variation in these measurements is thought to be due mainly to the inherent variability of the factors composing the yield calculation while recognizing that two of the experiments (ER 512-2 and ER579-1) might represent outliers. Naphthalene yield measurements without $\mathrm{NO}_{\mathrm{x}}$ were more consistent and systematically higher than the measurements with $\mathrm{NO}_{\mathrm{x}}$. $Y_{\text {SOA }}$ values were determined for resulting SOA levels from $22-158 \mu \mathrm{g} \mathrm{m}^{-3}$ and ranged between 0.18 and 0.036 ; YSOC ranged between 0.08 and 0.20 . For the two systems at similar SOA concentrations, the yields tended to be higher for experiments without $\mathrm{NO}_{\mathrm{x}}$, although not outside the limit of uncertainty. With $\mathrm{NO}_{\mathrm{x}}$ present, reactions of naphthalene tend to generate carbonyl products which is expected to lower the degree of SOC formation over the time scale of these experiments. However, in these experiments, there is no conclusive evidence that $Y_{\mathrm{SOA}}$ was lower at the lower SOA concentrations. For the experiments with the methyl naphthalenes (1-MN and 2-MN), only a few measurements were made and the yields were higher in the absence of $\mathrm{NO}_{\mathrm{x}}$ than with $\mathrm{NO}_{\mathrm{x}}$ in the system. In addition, flow- mode experiments without $\mathrm{NO}_{\mathrm{x}}$ were prone to producing high levels of aerosol $\left(>100 \mu \mathrm{g} \mathrm{m}^{-3}\right)$.

The major particulate-phase product produced in the naphthalene oxidation was phthalic acid which is an aromatic diacid (1,2-dicarboxybenzene) having a compound molecular weight $\left(M_{\mathrm{C}}\right)$ of $166 \mathrm{~g} \mathrm{~mol}^{-1}$ and a derivative molecular weight $(\mathrm{M})$ of $310 \mathrm{~g} \mathrm{~mol}^{-1}$. The derivatized compound is easily detected from the extracts of the aerosol phase. Both the electron ionization and the chemical ionization mass spectra of the derivative are presented in Fig. 1. For the CI spectra, a full set of fragments and adducts are detected. Characteristic ions of the derivatives are $m / z 73\left[\mathrm{Si}-\left(\mathrm{CH}_{3}\right)_{3}\right]^{+}, 75\left[\mathrm{HO}=\mathrm{Si}\left(\mathrm{CH}_{3}\right)_{2}\right]^{+}$and 147 $\left[\left(\mathrm{CH}_{3}\right)_{2} \mathrm{Si}=\mathrm{OSi}\left(\mathrm{CH}_{3}\right)_{3}\right]^{+}$; the pseudo molecular ions which include $\mathrm{M}+147\left[\mathrm{M}+\left(\mathrm{CH}_{3}\right)_{2} \mathrm{Si}=\mathrm{OSi}\left(\mathrm{CH}_{3}\right)_{3}\right]^{+}, \mathrm{M}+73[\mathrm{M}+$ $\left.\mathrm{Si}-\left(\mathrm{CH}_{3}\right)_{3}\right]^{+}, \mathrm{M}+41[\mathrm{M}+\mathrm{SiCH}]^{+}, \mathrm{M}+29\left[\mathrm{M}+\mathrm{C}_{2} \mathrm{H}_{5}\right]^{+}$, $\mathrm{M}+1[\mathrm{M}+\mathrm{H}]^{+}, \mathrm{M}-15\left[\mathrm{M}-\mathrm{CH}_{3}\right]^{+}$, and the base ion - M$89\left[\mathrm{M}-\mathrm{OSi}\left(\mathrm{CH}_{3}\right)_{3}\right]^{+}$are also all present (Jaoui et al., 2004). In general, CI mass spectrum from the laboratory samples show stronger adduct formation than do the field samples where the M-15 and M-89 fragments dominate. In addition to phthalic acid, field and laboratory samples often show the presence of isophthalic acid (IPhA; 1,3-dicarboxybenzene) and terephthalic acid (TPhA; 1,4-dicarboxybenzene), both of which regularly show dominate M-15 base ions (compared to the PhA base ion of M-89). For the EI spectra of phthalic acid, the two most intense peaks result from the characteristic ions $m / z 73$ and $m / z, 147$ (base ion). Other minor ions including M+147, M+73, M-15, and M-89 all of which have intensities of about $10 \%$ of the base ion. For measurements using EI, an authentic standard which has been derivatized is essential for retention time comparison to the field analyte for identification and quantification.

The napthalene irradiations, both with or without $\mathrm{NO}_{\mathrm{x}}$ present, produced phthalic acid in the aerosol phase as the chemical constituent with the highest yield. Table 4 gives absolute PhA concentrations together with the SOA mass formed in each experiment with calibrations based on authentic PhA standards. The mass fraction in each case is in the low single-digit percent range regardless of conditions. For experiments without $\mathrm{NO}_{\mathrm{x}}$, the mass fractions averaged $0.0201 \pm 0.0027$ giving a relative standard deviation of less than $15 \%$. The mass fraction with $\mathrm{NO}_{\mathrm{x}}$ averaged $0.0199 \pm 0.0084$. The relative standard deviation of $40 \%$ appears to be due to the different initial conditions of the experiments, including the fact that some were conducted with $\mathrm{CH}_{3} \mathrm{ONO}$ in the system. Mass fractions for phthalic acid 
Table 4. Phthalic acid concentrations $\left(\mathrm{ng} \mathrm{m}^{-3}\right)$ and mass fractions from laboratory irradiations of naphthalene. Since the mass fraction is a relative parameter, values are uncorrected for chamber losses.

\begin{tabular}{|c|c|c|c|c|c|c|}
\hline Expt No. & $\begin{array}{l}\text { SOA mass } \\
\left(\mu \mathrm{g} \mathrm{m}^{-3}\right)\end{array}$ & $\begin{array}{l}\text { Phthalic acid } \\
\left(\mu \mathrm{g} \mathrm{m}^{-3}\right)\end{array}$ & $\begin{array}{l}\text { Phthalic acid } \\
\left(\mu \mathrm{g} \mathrm{m}^{-3}\right)\end{array}$ & $\begin{array}{l}\text { Methylphthalic acid } \\
\left(\mu \mathrm{g} \mathrm{m}^{-3}\right)\end{array}$ & $\begin{array}{l}\text { SOA mass } \\
\text { fraction }^{\mathrm{a}}\end{array}$ & $\begin{array}{l}\text { SOA mass fraction } \\
\mathrm{b}\end{array}$ \\
\hline \multicolumn{7}{|c|}{$\mathrm{C}_{10} \mathrm{H}_{8} \mathrm{w}-\mathrm{NO}_{\mathrm{x}}$} \\
\hline $\mathrm{ER} 457^{\mathrm{c}}$ & 111.7 & 2.64 & 2.34 & & 0.0236 & 0.0209 \\
\hline ER458 & 101.1 & 3.20 & 2.96 & & 0.0316 & 0.0293 \\
\hline ER459-1 & 71.0 & 0.73 & 0.19 & & 0.0103 & $0.0027^{\mathrm{d}}$ \\
\hline ER459-2 & 92.4 & 1.28 & 2.24 & & 0.0139 & 0.0243 \\
\hline ER512 & 92.9 & 1.85 & 0.72 & & 0.0199 & 0.0078 \\
\hline Avg. \pm S.D. & & & & & $0.0199 \pm 0.0084$ & $0.0206 \pm 0.0092$ \\
\hline \multicolumn{7}{|c|}{$\mathrm{C}_{10} \mathrm{H}_{8}$ w/o- $\mathrm{NO}_{\mathrm{x}}$} \\
\hline $\mathrm{ER} 460-1 a^{\mathrm{e}}$ & 119.3 & 2.31 & 1.91 & & 0.0193 & 0.0160 \\
\hline ER460-1 $1 b^{\mathrm{e}}$ & 127.4 & 2.66 & 1.87 & & 0.0209 & 0.0147 \\
\hline ER460-2 & 113.8 & 2.32 & 1.90 & & 0.0204 & 0.0167 \\
\hline $\mathrm{ER} 461-1 a^{\mathrm{e}}$ & 17.6 & 0.25 & & & 0.0142 & \\
\hline $\mathrm{ER} 461-1 b^{\mathrm{e}}$ & 19.9 & 0.38 & & & 0.0189 & \\
\hline Avg. \pm S.D. & & & & & $0.0188 \pm 0.0027$ & $0.0158 \pm 0.0010$ \\
\hline \multicolumn{7}{|l|}{$1-\mathrm{C}_{11} \mathrm{H}_{10}$} \\
\hline ER467 & 77.0 & 0.48 & 0.67 & 0.26 & 0.0062 & 0.0087 \\
\hline ER470-1 & 32.6 & 0.29 & 0.37 & 0.02 & 0.0089 & 0.0113 \\
\hline ER470-2 & 62.6 & 0.21 & 0.89 & 0.02 & 0.0034 & 0.0142 \\
\hline \multicolumn{7}{|l|}{$2-\mathrm{C}_{11} \mathrm{H}_{10}$} \\
\hline ER468 ${ }^{\mathrm{f}}$ & 160.2 & 0.91 & 0.29 & 0.29 & 0.0057 & 0.0018 \\
\hline ER469-1 & 27.3 & 1.58 & 0.79 & 0.27 & 0.0579 & 0.0289 \\
\hline ER469-2 & 31.3 & 0.67 & 0.35 & 0.09 & 0.214 & 0.0113 \\
\hline
\end{tabular}

${ }^{a}$ Based on PhA calibration. ${ }^{b}$ Based on KPA calibration. ${ }^{c}$ Static- (aka, batch-) mode experiment. ${ }^{\mathrm{d}}$ Not used in average (outlier). ${ }^{\mathrm{e}}$ Parallel sample from a single sampling period. ${ }^{\mathrm{f}} \mathrm{NO}_{\mathrm{X}}$ absent from reactant mixture.

which were based on KPA as the calibration standard were reasonably consistent with those based on the $\mathrm{PhA}$ standards as seen in the adjoining columns in Table 4. For application with ambient $\mathrm{PhA}\left(\mathrm{ng} \mathrm{m}^{-3}\right)$, a mass fraction of 0.0199 should be used in conjunction with the mass fractions of Kleindienst et al. (2007).

Experiments from the photooxidation of 1-MN and 2-MN produced in addition to phthalic acid, several isomers of methyl phthalic acid. The different isomers (1MPhA-1 to -3; and $2 \mathrm{MPhA}-1$ to -2 ) are formed for individual photooxidation of 1-MN and 2-MN and are most clearly distinguished for irradiations without $\mathrm{NO}_{\mathrm{x}}$ in the system. Figure 2 presents GC chromatograms of the four isomers, two from each irradiation in the absence of $\mathrm{NO}_{\mathrm{x}}$. At the present time it is not possible to ascribe the positions of the methyl group with respect to the two acid groups since neat standards are not available.

Measurements were made in the laboratory to examine the potential role of gas phase phthalic anhydride in interfering with the filter measurements of phthalic acid. The experiments were designed to be an upper bound estimate for the gas-phase artifact for the filter collection of particle-bound phthalic acid in the presence of gas-phase phthalic anhydride. The experiments also examined the difference between phthalic acid collection on quartz filters (for field measurements) and glass-fiber filters (laboratory measurements). The experiments indicated that for a molar ratio of approximately twenty times more phthalic anhydride in the gas-phase than phthalic acid in the particle phase an increase of approximately $40 \%$ of phthalic acid was detected on the quartz filters. Moreover, there was a negligible difference (ca. $4 \%$ ) between use of TGIF and quartz filters for parallel sampling configurations.

The relevance in these aromatic diacids can be seen from samples taken during two recent field studies conducted in Southern California. Figure 3 shows a selected ion chromatogram from a composited derivatized sample taken during the Study of Organic Aerosols in Riverside (SOAR-1) conducted in 2005 in Riverside, CA (Docherty et al., 2008). For this figure, the M-15 ion has been extracted $(\mathrm{m} / z 295$ for PhA, IPhA, TPhA and $m / z 309$ for 2MPhA-2) to clearly show the presence of the compounds in the field sample. A 


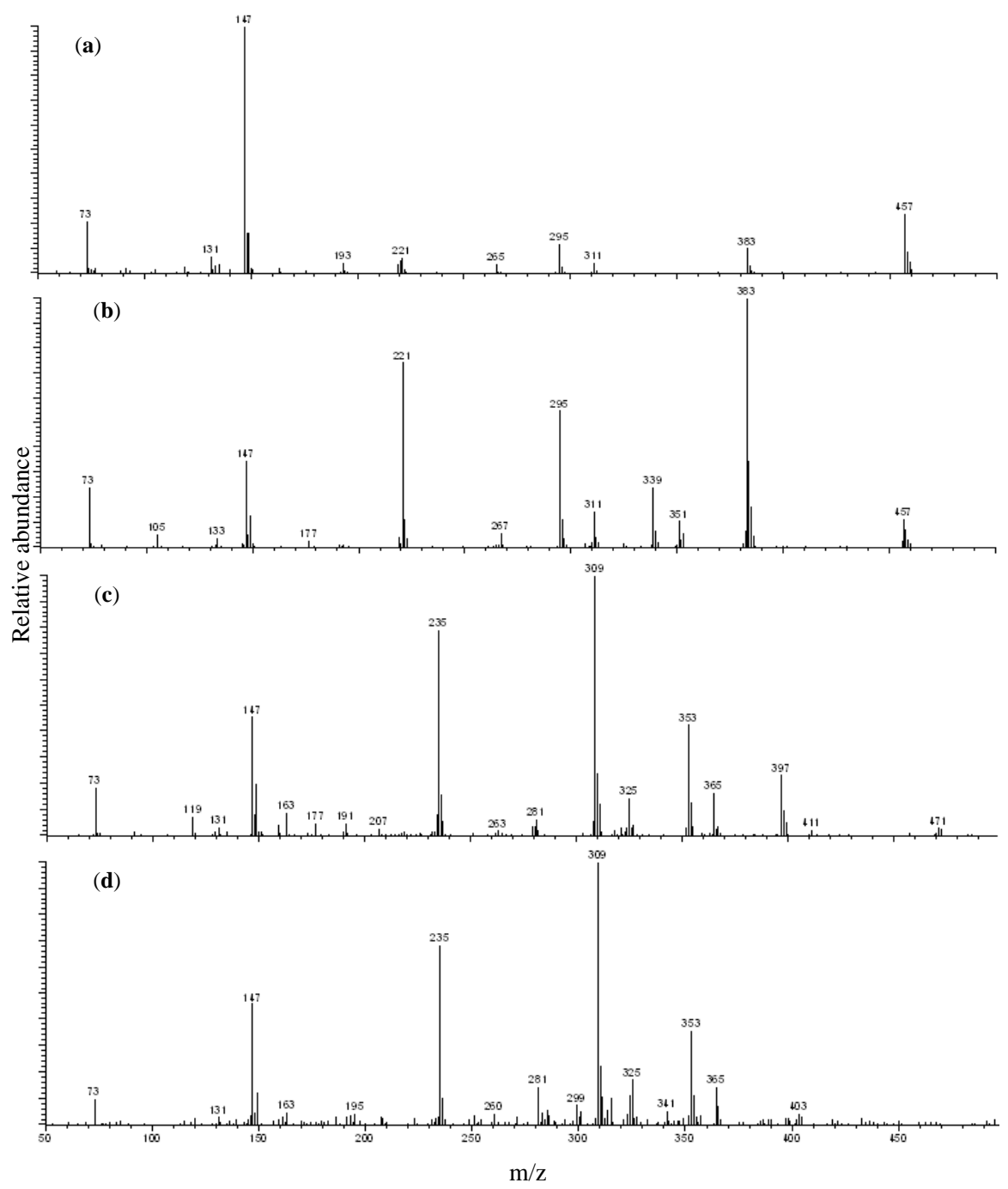

Fig. 1. Electronic ionization (a) and chemical ionization (b) mass spectra of phthalic acid from the GC-MS analysis of aerosol in Experiment ER512 and CI mass spectra of (c) 2-methylphthalic acid-isomer-2 (2MPhA-2; see text) from laboratory experiment, ER468 and (d) from the SOAR field study (see text). The major characteristic ions of the BSTFA derivatives, $m / z \quad 73\left[\mathrm{Si}-\left(\mathrm{CH}_{3}\right)_{3}\right]^{+}$and 147 $\left[\left(\mathrm{CH}_{3}\right)_{2} \mathrm{Si}=\mathrm{OSi}\left(\mathrm{CH}_{3}\right)_{3}\right]^{+}$, are seen to dominate the EI spectrum leaving the identifying fragments and adduct peaks at intensities typically less than $20 \%$ of the base ion.

comparison of the retention times of the MPhA peak relative to phthalic acid (in Fig. 2) indicates that the isomer seen in the field sample is 2MPhA-2. Similarly, other composited samples during this study showed the presence of these compounds.

Phthalic acid and MPhA were quantified for composited sampling periods during this study as presented in Fig. 4. Separate composites were taken for three 5-h time periods during the day and a single 9-h period at night. Samples were also segregated according to weekend and weekday periods. Weekday concentrations for $\mathrm{PhA}$ ranged from 2$10 \mathrm{ng} \mathrm{m}^{-3}$ and peak values occurred in the 15:00-20:00 $\mathrm{h} \mathrm{pe-}$ riod; by contrast, much higher levels of $\mathrm{PhA}\left(5-30 \mathrm{ng} \mathrm{m}^{-3}\right)$ were measured from the weekend samples with peak values occurring during the 10:00-15:00 $\mathrm{h}$ period. These trends are similar to the findings of Stone et al. (2009) for composite SOA. MPhA given in Fig. 2 as the 2MPhA-2 isomer typically followed the $\mathrm{PhA}$ time profiles with concentrations a factor of 5-10 lower.

The presence of phthalic acid and MPhA was also detected in filter samples taken during the CalNex Study conducted in Pasadena, CA during May and June of 2010. Samples were taken during 30 consecutive days during which $\mathrm{PhA}$ and MPhA were only seen during periods of relatively high photochemical activity. Figure 5 gives the profile of the ambient concentrations of PhA which peaked above $5 \mathrm{ng} \mathrm{m}^{-3}$ during three periods in the study. In addition, during periods of low activity, PhA concentrations were found to be below 


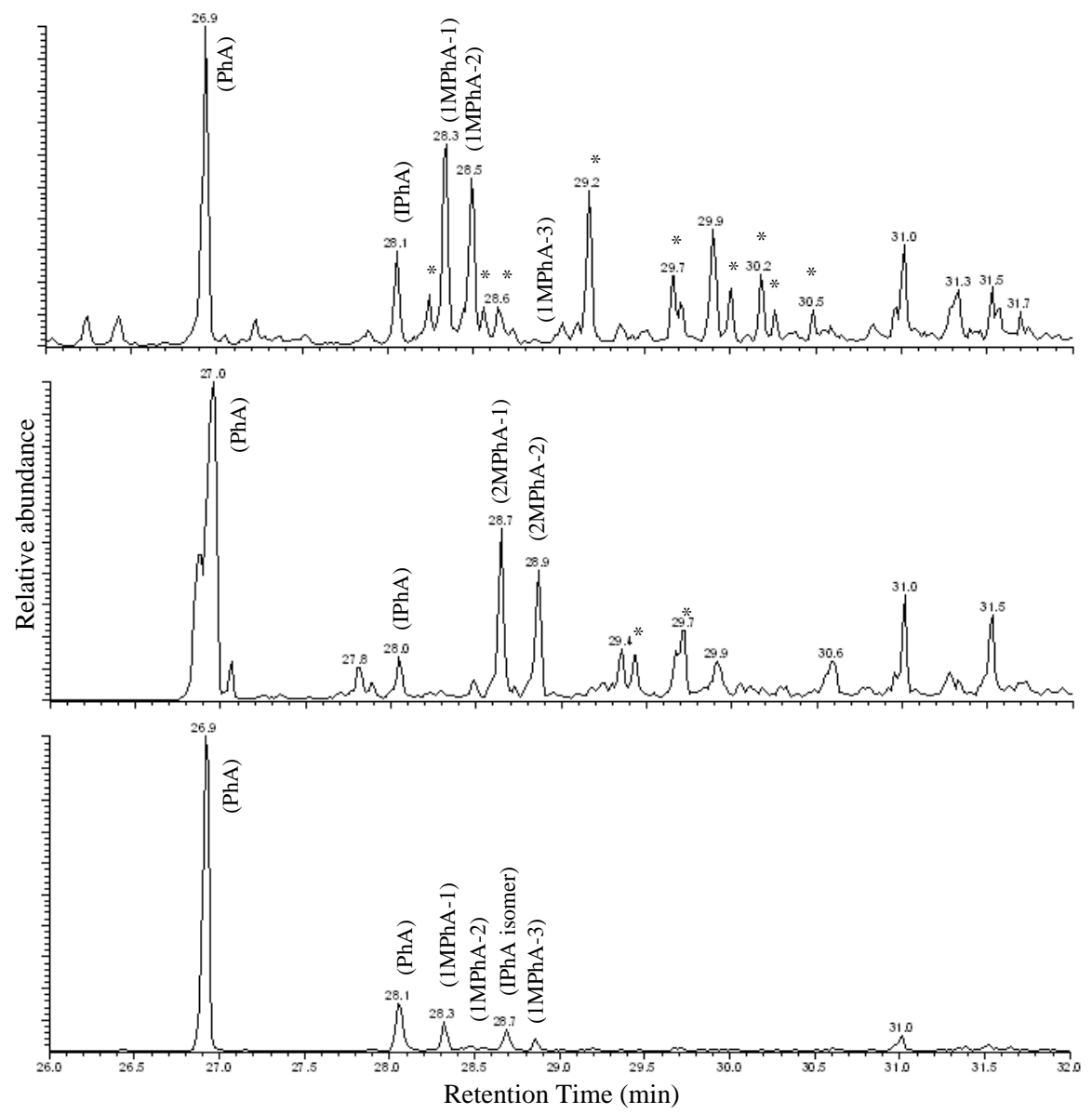

Fig. 2. The relative abundance vs. retention times are presented for the GC-MS chromatograms of the TMS-derivatives of phthalic acid (PhA), isophthalic acid (IPhA), 1-methylphthalic acid (1MPhA-1 to -3) and 2-methylphthalic acid (2MPhA-1 to -2) isomers from the photooxidation of 1-MN (top: absence of $\mathrm{NO}_{\mathrm{x}}$, bottom: presence of $\mathrm{NO}_{\mathrm{x}}$ ) and 2-MN (middle: absence of $\mathrm{NO}_{\mathrm{x}}$ ) from ER467, ER470, and ER468, respectively. The peaks are scaled using the M-15 peak ( $m / z 295$ for PA and $m / z 309$ for $1 \mathrm{MPhA}-1$ to -3 and $2 \mathrm{MPhA}-1$ to -2$)$. For the experiments in the presence of $\mathrm{NO}_{\mathrm{x}}$ the ratio of the $\Sigma \mathrm{MPhA}$ to PhA is considerably lower using the ion scaling shown here. $(*)$ represent peaks having similar mass spectra as $1 \mathrm{MPhA}$ or $2 \mathrm{MPhA}$.

the detection limit of approximately $0.1 \mathrm{ng} \mathrm{m}^{-3}$. Again, this 2MPhA-2 isomer was the only methyphthalic acid isomer detected in these ambient samples.

\section{Discussion}

Polycyclic aromatic hydrocarbons have been found to be emitted from the combustion of fossil-fuels, for example, through diesel exhaust emissions (Schauer et al., 1999). Compounds with fewer than four fused-rings are generally found almost exclusively in the gas phase with the naphthalene concentration typically being higher than the sum of all other PAHs. The gas-phase oxidation of naphthalene has been addressed in several studies. Similar to benzene, the naphthalene reacts (during the day) by the addition of hydroxyl radicals $(\mathrm{OH})$ to the aromatic ring, here at either the 1- or 2-position. Unlike benzene, the rate constant for the reaction is extremely high at $2.4 \times 10^{-11} \mathrm{~cm}^{3} \mathrm{molec}^{-1} \mathrm{~s}^{-1}$ (Biermann et al., 1985). The initial carbon-center radical can add $\mathrm{O}_{2}$ or $\mathrm{NO}_{2}$ depending on the $\mathrm{NO}_{2}$ concentration present yielding potentially different gas-phase product distributions (see below). Reaction products lead to both ring-retaining and ring-cleavage products. Ring cleavage products tend to predominate under conditions where NO reacts with the initially formed peroxy radicals. The major product from the primary reaction is 2-formylcinnamaldehyde with a reported yield of 0.56 (Nishino et al., 2009a). This compound, while reacting extremely rapidly with $\mathrm{OH}$, is also highly prone to photolysis at actinic wavelengths.

Acyclic ring-cleavage products have also been reported although at relatively low yield. Thus, the photooxidation of naphthalene has been found to generate glyoxal as a primary product at yields of 0.05 (Nishino et al., 2009b). The coproduct of this reaction, phthaldialdehyde (i.e., 1,2-dialdehydic 


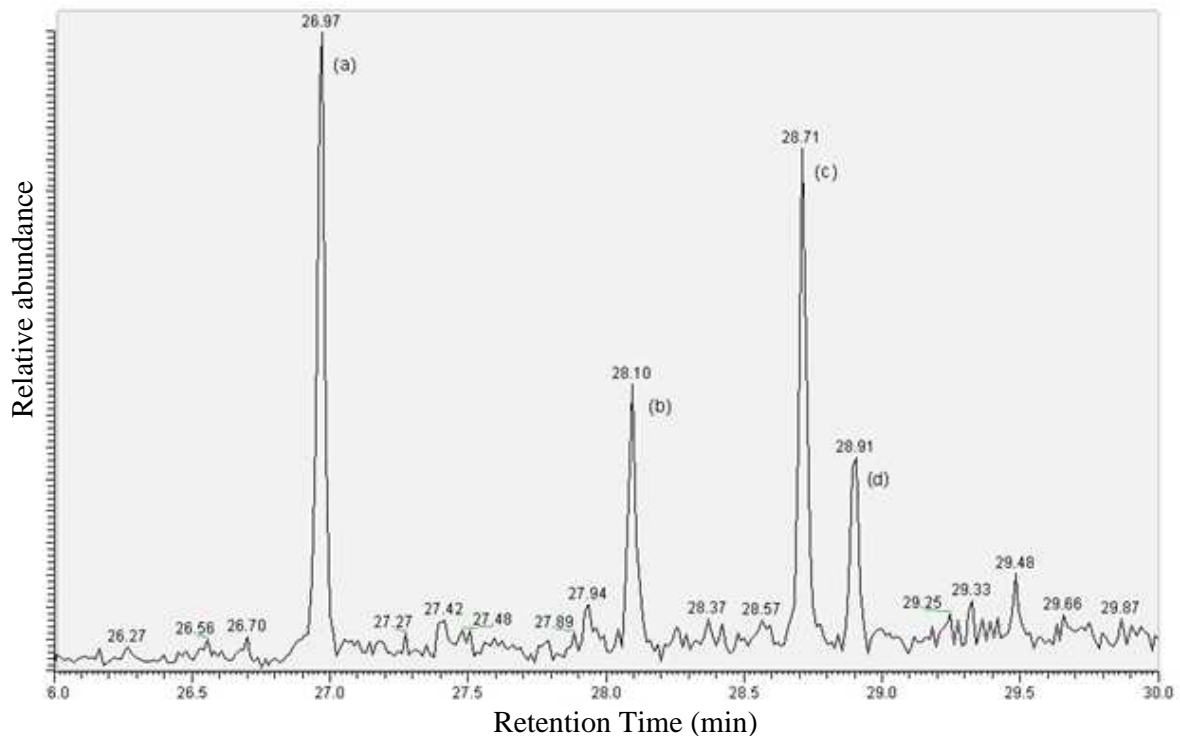

Fig. 3. GC-MS chromatogram vs. retention time for a sample taken during the SOAR Study in Riverside, CA in 2005. The chromatogram presents the TMS-derivatives of the PhA isomers and methyl phthalic acid from a composited sample taken weekdays between 05:00-10:00 a.m. Peaks are scaled by the M-15 ion intensities and include (a) phthalic acid; (b) isophthalic acid; (c) terephthalic acid (presumed, coeluted with an interfering compound); and (d) the single methylphthalic acid isomer (2MPhA-2) which was detected.

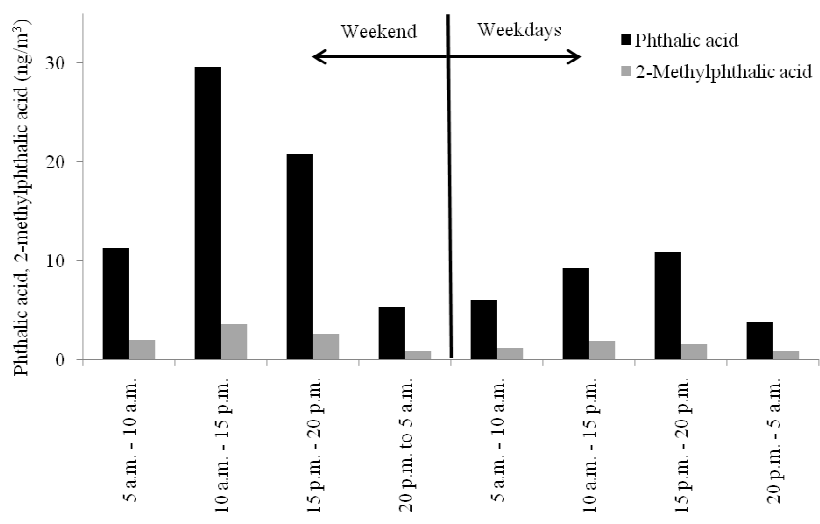

Fig. 4. Time profiles for the TMS-derivatives of phthalic acid ( $\mathrm{PhA}$; $\mathrm{ng} \mathrm{m}^{-3}$ ) and 2-methylphthalic acid (2MPhA-2; see Fig. 2) during the 2005 SOAR Study in CA. Calibrations for both compounds are based on external PhA standards. SOA upper limit contributions "as naphthalene" can be determined from dividing the $\mathrm{PhA}$ values by the SOA mass fraction from Table 4.

benzene) has also been detected. While secondary formation of glyoxal is also possible from a secondary reaction of $\mathrm{OH}$ with 2-formylcinnamaldehyde, the phthaldialdehyde appears to be formed only in the primary reaction of naphthalene. Phthaldialdehyde has been found to undergo further reaction with $\mathrm{OH}$ to generate phthalic anhydride (Wang et al., 2007) which appears to be relatively stable in the absence of hydrolysis.

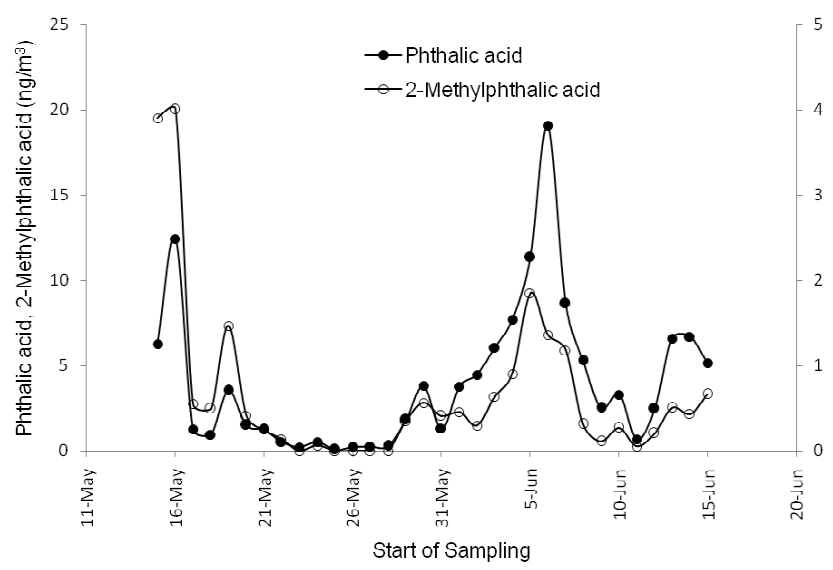

Fig. 5. Time profiles for the TMS-derivatives of phthalic acid (ng $\mathrm{m}^{-3}$; left scale) and methylphthalic acid (right scale) during the 2010 CalNex Study in Pasadena, CA. Negligible levels of phthalic acid during the periods between 23-29 May and 9-11 June 2010 are indicative of the likely negligible emissions of phthalic acid and methylphthalic acid during this study. Calibrations for both compounds are based on external $\mathrm{PhA}$ standards. SOA upper limit contributions "as naphthalene" can be determined from dividing the $\mathrm{PhA}$ values by the SOA mass fraction of 0.0199 from Table 4 .

For the two methyl naphthalenes, in the addition reaction to the aromatic ring, $\mathrm{OH}$ can also react by abstracting a hydrogen atom (H-atom) from the substituent methyl group. The $\mathrm{OH}$ rate constants for methyl naphthalenes have been found to be about a factor of two higher than that for 
naphthalene (Phousongphouang and Arey, 2002).Subsequent fast reactions lead to low yields of 1-naphthoic acid (e.g., from 1-methylnaphthalene) by analogy to benzoic acid from methyl substituted aromatic hydrocarbons. An examination of the extracted organic aerosol indicated negligible levels of either 1- or 2-naphthoic acid in the particle phase. However, ring-addition reactions predominate at atmospheric temperatures and $\mathrm{NO}_{2}$ concentrations. Since 1-MN and 2-MN lack the symmetry of naphthalene, additional dicarbonyl products (i.e., methylglyoxal) can form. Thus, for $\mathrm{OH}$ addition to the most substituted ring of the methyl naphthalenes (either 1-MN or 2-MN), methylglyoxal and its coproduct, phthaldialdehyde will be formed. Reactions of phthaldialdehyde will be identical to those of the naphthalene case and phthalic anhydride will form in the gas-phase, probably resulting in phthalic acid being formed in the particle phase. By contrast, if $\mathrm{OH}$ adds to the least substituted ring, glyoxal and its coproduct, 1-methyl-2,3-dicarbonyl benzene (or other geometric or substitution isomers) will be formed. By analogy to naphthalene, this compound via secondary reactions will form methyl phthalic anhydride (and other geometric isomers). Mechanisms for these processes are analogous to those for naphthalene presented by Kautzmann et al. (2010).

The formation of secondary organic aerosol from the photooxidation of naphthalene has previously been shown to occur both in the presence and absence of $\mathrm{NO}_{\mathrm{x}}$ (Chan et al., 2009; Kautzman et al., 2010; Shakya and Griffin, 2010). While Kautzman et al. (2010) focused on the identification of individual chemical products in the gas and particle phase, Chan et al. (2009) considered the aerosol yield under a variety of reactant conditions for naphthalene and $\mathrm{NO}_{\mathrm{x}}$. Shakya and Griffin (2010) also examined aerosol yields under somewhat lower initial $\mathrm{NO}$ and in the absence of seed aerosol.

In the studies of Chan et al. (2009), aerosol yields were measured under high- $\mathrm{NO}_{\mathrm{x}}$ conditions with aerosol loadings ranging from $10-40 \mu \mathrm{g} \mathrm{m}^{-3}$ with evidence for semivolatile partitioning from these experiments. Under conditions where $\mathrm{NO}_{\mathrm{x}}$ was absent from the experiments, the products appeared to be nonvolatile and aerosol yields were found to be a constant regardless of the associated organic aerosol mass. Table 5 shows a comparison of the yields from the work of Chan et al. (2009) and results of the experiments in the current work. For experiments at high $\mathrm{NO}_{\mathrm{x}}$ levels, Chan et al. (2009) provide parameterization for SOA partitioning for naphthalene as, $\alpha_{1} 0.21, \alpha_{2} 1.07, K_{1} 0.59, K_{2} 0.0037$, for the two product model. Aerosol yields have also been examined by Shakya and Griffin (2010), who in the experimental yield data they present show a nearly constant yield of 0.15 over organic aerosol concentrations from $5-25 \mu \mathrm{g} \mathrm{m}^{-3}$, indicating that partitioning may be playing a minor role in the aerosol products generated. Nonetheless, Shakya and Griffin (2010) present parameters for a two-product model for naphthalene SOA formation that assumes partitioning.

For 1-methylnaphthalene, and 2-methylnaphthalene, parameterization for a single product model is provided with $\alpha_{1}$
$0.50, K_{1} 0.11$ (for $1-\mathrm{MN}$ ) and $\alpha_{1} 0.55, K_{1} 0.13$ (for 2-MN). For yields measured at high $\mathrm{NO}_{\mathrm{x}}$, the comparison shows that the yields are within a factor of two when the values are compared at the same $\Delta \mathrm{M}_{\mathrm{O}}$. For the reaction in the absence of $\mathrm{NO}_{\mathrm{x}}$, yields for SOA formation for naphthalene between the two studies differ by nearly a factor of three. While yield differences are far less for the methyl naphthalenes, there is a different trend. For Chan et al. (2009) the SOA yields decrease in going from naphthalene to 1-methylnaphthalene to 2-methylnaphthalene whereas in the present work the yields increase. In a manner consistent with the $n$-alkane yields, the aerosol yields from experiments conducted with the chamber operating in a flow mode are found to be systematically lower than those determined with the chamber operated in a static mode, in particular for SOA formed from naphthalene.

Unlike the degradation mechanism of other more volatile VOCs, such as the $\mathrm{C}_{7}-\mathrm{C}_{9}$ mono and multi methyl aromatic hydrocarbons, the photooxidation of naphthalene in the laboratory (also methylnaphthalenes and possibly other PAHs) are likely to form SOA while NO is still present in the oxidation system to a substantial degree (e.g., Robinson et al., 2007). Thus, early generation products in this system could be of sufficiently low volatilities (probably from radical terminating reactions) to condense onto preexisting aerosol. For PAHs and monoaromatic hydrocarbons, the initial $\mathrm{OH}-$ addition adduct can react with $\mathrm{NO}_{2}$ to form nitro compounds as early reaction products, which are detected in the gas phase (Nishino et al., 2008). The extent to which such compounds partition to form SOA could be a consideration in this work but has not been explored. However, as seen in Table 5, the yields determined in this study at high organic loading suggest that while the gas-phase product distribution may differ with $\mathrm{NO}_{2}$ levels, the SOA formation yields appear to be insensitive to this, as seen by the $\mathrm{NO}_{\mathrm{x}}$-free initial conditions.

Measurements of the effective enthalpy of vaporization for the aerosol give values ranging between 15 and $20 \mathrm{~kJ} \mathrm{~mol}^{-1}$. The range of values is similar to that found for SOA during toluene photooxidation, although higher (less negative) than that of other methylated aromatic hydrocarbons, such as the xylenes and trimethylbenzenes, which average 30 to $40 \mathrm{~kJ} \mathrm{~mol}^{-1}$. Typically, precursors that generate relatively large yields of glyoxal, such as toluene, benzene (MartinReviejo and Wirtz, 2005), and acetylene (Volkamer et al., 2008), show aerosol yields that are higher than might be expected for such small molecules. $\Delta H_{\text {vap }}^{\text {eff }}$ values in the same range were found for 1-MN and 2-MN as in the naphthalene system (both with and without $\mathrm{NO}_{\mathrm{x}}$ ) suggesting that the methyl group plays little role in changing the volatility of the aerosol compared to naphthalene. It is expected that the methyl glyoxal formation is relatively low and does not impact the volatility of the chamber aerosol.

The OM/OC ratios for the naphthalene systems with and without $\mathrm{NO}_{\mathrm{x}}$ are consistent. For the $\mathrm{NO}_{\mathrm{x}}$ system, an average value of 1.93 was found ( $n=7$; Table 3 ); for the $\mathrm{NO}_{\mathrm{x}}$-free 
Table 5. Comparison of aerosol yields for SOA $Y_{\mathrm{SOA}}$ from $\mathrm{PAH}$ photooxidations for different initial $\mathrm{NO}_{\mathrm{x}}$ conditions.

\begin{tabular}{lllll}
\hline PAH & $\begin{array}{l}Y_{\text {SOA }} \\
\text { (Chan et al., 2009) }^{\mathrm{a}}\end{array}$ & $\begin{array}{l}Y_{\text {SOA }} \\
(\text { Chan et al., 2009) }\end{array}$ & $\begin{array}{l}\text { Shakya and } \\
\text { Griffin (2010) }\end{array}$ & $\begin{array}{l}Y_{\text {SOA }} \\
\text { (this study) }\end{array}$ \\
\hline Naphthalene (high $\mathrm{NO}_{\mathrm{x}}$ ) & 0.24 & 0.49 & $(0.08-0.16)^{\mathrm{c}}$ avg: 0.13 & $0.28^{\mathrm{d}}$ \\
1-Methylnaphthalene (high $\left.\mathrm{NO}_{\mathrm{x}}\right)$ & 0.31 & 0.46 & $(0.03-0.22)$ & 0.20 \\
2-Methylnaphthalene (high $\left.\mathrm{NO}_{\mathrm{x}}\right)$ & 0.36 & 0.51 & $(0.04-0.13)$ & 0.15 \\
Naphthalene $^{\mathrm{e}}\left(\right.$ low $\left.\mathrm{NO}_{\mathrm{x}}\right)$ & 0.73 & 0.73 & - & 0.28 \\
1-Methylnaphthalene $^{\mathrm{e}}\left(\right.$ low $\left.\mathrm{NO}_{\mathrm{x}}\right)$ & 0.68 & 0.68 & - & 0.41 \\
2-Methylnaphthalene $^{\mathrm{e}}\left(\right.$ low $\left.\mathrm{NO}_{\mathrm{x}}\right)$ & 0.58 & 0.58 & - & 0.64 \\
\hline
\end{tabular}

a Aerosol yield at $\Delta \mathrm{M}_{\mathrm{O}} 15 \mu \mathrm{g} \mathrm{m}{ }^{-3}$; chamber operated in static mode; ${ }^{\mathrm{b}}$ aerosol yield at $\Delta \mathrm{M}_{\mathrm{O}} 100 \mu \mathrm{g} \mathrm{m}^{-3} ;{ }^{\mathrm{c}} \Delta \mathrm{M}_{\mathrm{O}} 4-18 \mu \mathrm{g} \mathrm{m} \mathrm{m}^{-3}$, apparent constant yield with $\Delta \mathrm{M}_{\mathrm{O}} ;{ }^{\mathrm{d}} 0.14 \mathrm{ppm} ; \mathrm{CH}_{3} \mathrm{ONO}, 0.3 \mathrm{ppm} \mathrm{NO}$ with chamber in dynamic mode, for $\Delta \mathrm{M}_{\mathrm{O}} 100 \mu \mathrm{g} \mathrm{m}^{-3} ;{ }^{\mathrm{e}}$ products found to be nonvolatile and SOA yield is constant at all $\Delta \mathrm{M}_{\mathrm{O}}$.

system, values ranged between 1.9-2.3 giving an average value of $2.01(n=3)$. While averaging the two conditions given an overall average of 1.97 , under relevant atmospheric conditions, the value with $\mathrm{NO}_{\mathrm{x}}$ present should be used. Values in the same range were found for $1-\mathrm{MN}$ and $2-\mathrm{MN}$ in the $\mathrm{NO}_{\mathrm{x}}$-free system although the number of data points is extremely small and suggests that the methyl group plays little role in changing the oxygen content of the aerosol. At the present time, there does not appear to be literature data to compare to.

As noted, phthalic anhydride has been found to form as a secondary product at relatively high yields for naphthalene (Wang et al., 2007). It seems plausible that particle-phase phthalic acid is generated from the hydrolysis of phthalic anhydride (Chan et al., 2009) involving aerosol liquid water or possibly surface-adsorbed water. We have thus explored the use of phthalic acid as a tracer compound representative of SOA (and SOC) from the photooxidation of naphthalene both in the absence and presence of $\mathrm{NO}_{\mathrm{x}}$. Measurements of the phthalic acid yield have been made leading to a mass fraction of phthalic acid as given in Table 4. In this analysis, some caution must be exercised due to the possible appearance of outliers, for example, in experiment ER 459-1 the phthalic acid concentration appears to be systematically low using a standard based on KPA. The phthalic acid yields can then used in conjunction with in field samples to estimate contributions of SOA (and SOC) from naphthalene, methylnaphthalene, and possibly other 2-ring, gas-phase PAHs, in a source attribution approach similar to that of Kleindienst et al. (2007).

In this work, we have sought to evaluate multiple means for establishing $\mathrm{PhA}$ tracer concentrations that would allow greater utility for using the laboratory-produced mass fraction values without an over reliance on specific methods for measuring PhA concentrations. This has been done for several reasons: (1) standards are readily produced for phthalic acid, in contrast to many tracer compounds from other precursors (e.g., most classes of biogenic hydrocarbons) for which standards are typically not available. (2) Determination of tracer concentrations for phthalic acid (and methyl phthalic acid) are generally within the method uncertainty using either a neat standard or a general surrogate compound such as ketopinic acid, as seen in Table 4. (3) Other investigators (e.g., Hu et al., 2008) have already shown the usefulness of determining precursor contributions to secondary organic aerosol using alternate means of determining tracer concentrations. These investigations have shown that the use the laboratory-based mass fractions (e.g., Kleindienst et al., 2007) while still using their own laboratory protocols for determining the tracer concentrations $\left(\mathrm{ng} \mathrm{m}^{-3}\right)$ in the aerosol sample. Overall, the results have been reasonable.

Phthalic acid has been recognized as a chemical constituent in $\mathrm{PM}_{2.5}$ in ambient atmospheres over the past twenty years. Fine et al. (1994) suggested its use as a potential chemical tracer, although at that time only in a qualitative sense. As discussed by Kleindienst et al. (2007) the use of a chemical constituent as a tracer compound for secondary organic aerosol using the mass fraction approach is subject to a number of potential uncertainties including: (1) the possibility that the tracer compound(s) also has a primary source; (2) laboratory mass fractions are different from those found in ambient air; (3) secondary reaction of the tracer compound; (4) filter uptake of gas-phase compounds that can be converted to the chemical tracer; (5) differences in mass fractions from other 2-ring PAHs contributing to the observed $\mathrm{PhA}$ levels; and (6) the possibility of the gas-phase hydrolysis of phthalic anhydride which could make the tracer concentration be sensitive to the relative humidity in the ambient environment. The final point is unique to phthalic acid since the anhydride form of other acidic tracers is generally not recognized though theoretically possible for some of the tracer compounds (Kleindienst et al., 2007).

Conditions and results for tracer measurements have already been presented for the SEARCH sites (Kleindienst et al., 2010a) with the contribution of PAHs using phthalic acid recently being added to the total aerosol masses (SOA or SOC; Kleindienst et al., 2010b). Notably, these findings helped reduce a negative intercept (Kleindienst et al., 2010a; Fig. 1) from a plot of OC vs. reconstructed OC from primary and secondary SOC. In the derivatized spectra of the 
SEARCH sites, while there was clear evidence for the presence of phthalic acid, there was no evidence for any of the $\mathrm{MPhA}$ isomers which were detected in laboratory irradiations. An examination of derivatized spectra from the 2005 SOAR study (Docherty et al., 2008) showed the presence of Peak 4 of methylphthalic acid, 2MPhA-2 as seen in Fig. 3. For the eight periods that samples were taken, methylphthalic acid was clearly detected from the derivatized extracts from each of those periods as seen in Fig. 4.

Finally, measurements were made for phthalic and methylphthalic acid during the 2010 CalNex Study (Washenfelder et al., 2011). Figure 5 presents values of phthalic acid in Pasadena, CA during a one-month period which show values as high as $19 \mathrm{ng} \mathrm{m}^{-3}$ during periods when the organic carbon was also at its highest level during the study. Also notably, during several periods of low apparent photochemical activity, phthalic acid was at or below the detection limit estimated at $0.1 \mathrm{ng} \mathrm{m}^{-3}$ for the sampling volumes taken. To the extent that there are primary emissions of phthalic acid, they probably contribute on the order of $0.1 \mathrm{ng} \mathrm{m}^{-3}$ to the $\mathrm{PhA}$ mass on the filter. One of these period (23-29 May 2010) of $\mathrm{PhA}$ measurements near or below the detection limit includes both the weekend and weekdays. Thus, while primary sources of phthalic acid are possible, they do not appear to be important during the present study. The SOC source apportionment values for PAH SOA (as naphthalene) during this study period using an average mass fraction of 0.0199 (with $\mathrm{NO}_{\mathrm{x}}$ ) ranged from below the detection limit to $0.49 \mu \mathrm{gC} \mathrm{m} \mathrm{m}^{-3}$ as an upper limit. Using the $\mathrm{OM} / \mathrm{OC}$ ratio (1.93 presented earlier) the SOA contribution due to PAHs (as naphthalene) give a level of $1.0 \mu \mathrm{g} \mathrm{m}^{-3}$. The average contribution of SOC during the study using this approach was $0.10 \mu \mathrm{gC} \mathrm{m}^{-3}$ while an SOA average of $0.19 \mu \mathrm{g} \mathrm{m}^{-3}$ was determined.

The present experiments and field measurements illustrate the difficulty and confounding factors involved in the use of chemical tracers for estimating specific source attribution. Kautzman et al. (2010) have discussed other possible chemical tracers for secondary organic aerosol from naphthalene photooxidation including naphthol. However, to have utility as a chemical tracer, an approach for using it at ambient levels in a practical manner is needed. As noted in Kleindienst et al. (2007), the use of chemical tracers for estimation of secondary organic aerosol source attribution using the techniques described herein, while subject to numerous uncertainties, can play an important role in determining whether a hydrocarbon or class of hydrocarbons are significant contributors to ambient aerosol.

\section{Summary}

1. Phthalic acid is readily produced during the photooxidation of naphthalene in both the presence and absence of $\mathrm{NO}_{\mathrm{x}}$. Under the conditions of these experiments, the mass fraction of SOA for phthalic acid in the presence of $\mathrm{NO}_{\mathrm{x}}$ is $0.0199 \pm 0.0084$ and in the absence of $\mathrm{NO}_{\mathrm{x}}$ is $0.0188 \pm 0.0027$, where calibration factors have been based on $\mathrm{PhA}$ standards. Following our prior approach using ketopinic acid for calibration, the mass fractions are $0.0206 \pm 0.0092$ in the presence of $\mathrm{NO}_{\mathrm{x}}$ and $0.0158 \pm 0.0010$ in the absence of $\mathrm{NO}_{\mathrm{x}}$. These uncertainties represent the reproducibility of the experiments for the conditions selected and do not include other possible systematic errors. From the average OM/OC value of 1.93, an SOC mass fraction is determined using this value as a multiplicative factor with the SOA listed mass fractions.

2. The mass fractions reported herein have been applied to ambient data at CalNex to estimate the the 2-ring PAH contribution to SOC ranges from below the detection limit to levels as high as $0.49 \mu \mathrm{gC} \mathrm{m}^{-3}$. At the present time, these values must be considered upper limits due to the possible contribution of primary emissions of phthalic acid or from the hydrolysis of atmospheric phthalic anhydride. Additional uncertainties of the mass fraction approach for 2-ring PAHs follow those that have already been discussed in Kleindienst et al. (2007).

3. Phthalic acid and methylphthalic acid are detected in both laboratory and field samples. For methylphthalic acid, preferential ring scission on the most substituted aromatic ring leads to phthalic anhydride. Since 2ring PAH contributions are given "as naphthalene" any methylnaphthalene contributions are already included in the naphthalene attribution.

4. Mass fractions for phthalic acid were determined using calibrations based on the pure compound, as well as on ketopinic acid (KPA). The two approaches were used for consistency with previous work (Kleindienst et al., 2007) while recognizing that where authentic standards exist, calibrations from those compounds provide the most self consistent means for attributing sources under atmospheric concentrations.

Acknowledgements. The authors wish to thank J. J. Schauer of the University of Wisconsin - Madison for providing the filter samples used from the SOAR Study. The US Environmental Protection Agency through its Office of Research and Development funded and collaborated in the research described here under Contract EP-D-10-070 to Alion Science and Technology. The manuscript is subjected to external peer review and has been cleared for publication. Mention of trade names or commercial products does not constitute an endorsement or recommendation for use.

Edited by: R. McLaren 


\section{References}

Biermann, H. W., Mac Leod, H, Atkinson, R., Winer, A. M., and Pitts Jr., J. N.: Kinetics of the gas-phase reactions of the $\mathrm{OH}$ radical-initiated reactions of naphthalene and the $\mathrm{C}_{1}$ - and $\mathrm{C}_{2-}$ alkylnaphthalenes, Environ. Sci. Technol., 41, 2803-2810, 2007.

Birch, M. E. and Cary, R. A.: Elemental carbon-based method for monitoring occupational exposures to particulate diesel exhaust, Aerosol Sci. Technol., 25, 221-241, 1996.

California Air Resources Board: Ambient Concentrations of Polycyclic Aromatic Hydrocarbons (PAHs) at Selected Locations in California, Research Note No. 89-1, 1989.

Chan, A. W. H., Kautzman, K. E., Chhabra, P. S., Surratt, J. D., Chan, M. N., Crounse, J. D., Kürten, A., Wennberg, P. O., Flagan, R. C., and Seinfeld, J. H.: Secondary organic aerosol formation from photooxidation of naphthalene and alkylnaphthalenes: implications for oxidation of intermediate volatility organic compounds (IVOCs), Atmos. Chem. Phys., 9, 3049-3060, doi:10.5194/acp-9-3049-2009, 2009.

Claeys, M., Szmigielski, R., Kourtchev, I., Van der Veken, P., Vermeylen, R., Maenhaut, W., Jaoui, M., Kleindienst, T. E., Lewandowski, M., Offenberg, J. H., and Edney, E. O.: Hydroxydicarboxylic acids: Markers for secondary organic aerosol from the photooxidation of $\alpha$-pinene, Environ. Sci. Technol., 41, 6828-6834, 2007.

deGouw, J. A., Middlebrook, A. M., Warneke, C., Goldan, P. D., Kuster, W. C., Roberts, J. M., Fehsenfeld, F. C., Worsnop, D. R., Canagaratna, M. R., Pszenny, A. A. P., Keene, W. C., Marchewka, M., Bertman, S. B., and Bates, T. S.: Budget of organic carbon in a polluted atmosphere: Results from the New England Air Quality Study in 2002, J. Geophys. Res., 110, D16305, doi.10.1029/2004JD005623, 2005.

deGouw, J. A., Brock, C. A., Atlas, E. L., Bates, T. S., Fehsenfeld, F. C., Goldan, P. D., Holloway, J. S., Kuster, W. C., Lerner, B. M., Matthew, B. M., Middlebrook, A. M., Onasch, T. B., Peltier, R. E., Quinn, P. K., Senff, C. J., Stohl, A., Sullivan, A. P., Trainer, M., Warneke, C., Weber, R. J., and Williams, E. J.: Sources of particulate matter in the northeastern United States in summer: 1. Direct emissions and secondary formation of organic matter in urban plumes, J. Geophys. Res., 113, D08301, doi:10.1029/2007JD009243, 2008.

Docherty, K. S., Stone, E. A., Ulbrich, I. M., DeCarlo, P. F., Snyder, D. C., Schauer, J. J., Peltier, R. E., Weber, R. J., Murphy, S. M., Seinfeld, J. H., Grover, B. D., Eatough, D. J., and Jimenez, J. L.: Apportionment of Primary and secondary organic aerosols in Southern California during the 2005 Study of Organic Aerosols in Riverside (SOAR-1), Environ. Sci. Technol., 42, 7655-7662, 2008.

Edney, E. O., Kleindienst, T. E., Jaoui, M., Lewandowski, M., Offenberg, J. H., Wang, W., and Claeys, M.: Formation of 2-methyl tetrols and 2-methylglyceric acid in secondary organic aerosol from laboratory irradiated isoprene $/ \mathrm{NO}_{\mathrm{x}} / \mathrm{SO}_{2}$ /air mixtures and their detection in ambient $\mathrm{PM}_{2.5}$ samples collected in the eastern U.S., Atmos. Environ., 39, 5281-5289, 2005.

Fine, P. M., Chakrabarti, B., Krudysz, M., Schauer, J. J., and Sioutas, C.: Diurnal variations of individual organic compound constituents of ultrafine and accumulation mode particulate matter in the Los Angeles basin, Environ. Sci. Technol., 38, 12961304, 2004.
Fraser, M. P., Cass, G. R., and Simoneit, B. R. T.: Air quality model evaluation data for organics. $6 . \mathrm{C}_{3}-\mathrm{C}_{24}$ organic acids, Environ. Sci. Technol., 37, 446-453, 2003.

Gundel, L. A., Lee, V. C., Mahanama, K. R. R., Stevens, R. K., and Daisey, J. M.: Direct determination of the phase distribution of semi-volatile polycyclic aromatic hydrocarbons using annular denuders, Atmos. Environ., 29, 1719-1733, 1995.

Hallquist, M., Wenger, J. C., Baltensperger, U., Rudich, Y., Simpson, D., Claeys, M., Dommen, J., Donahue, N. M., George, C., Goldstein, A. H., Hamilton, J. F., Herrmann, H., Hoffmann, T., Iinuma, Y., Jang, M., Jenkin, M. E., Jimenez, J. L., Kiendler-Scharr, A., Maenhaut, W., McFiggans, G., Mentel, Th. F., Monod, A., Prévôt, A. S. H., Seinfeld, J. H., Surratt, J. D., Szmigielski, R., and Wildt, J.: The formation, properties and impact of secondary organic aerosol: current and emerging issues, Atmos. Chem. Phys., 9, 5155-5236, doi:10.5194/acp-9-51552009, 2009.

Heald, C. L., Jacobs, D. J., Park, R. J., Russell, L. M., Huebert, B. J., Seinfeld, J. H., Liao, H., and Weber, R. J.: A large organic aerosol source in the free troposphere missing from current models, Geophy. Res. Lett., 32, L18809, doi:10.1029/2005GL023831, 2005.

Hu, D., Bian, Q., Li, T. W. Y., Lau, A. K. H., and Yu, J. $\mathrm{Z}$., Contributions of isoprene, monoterpenes, $\beta$-caryophyllene, and toluene to secondary organic aerosols in Hong Kong during the Summer of 2006, J. Geophys. Res., 113, D22206, doi:10.1029/2008JD010437, 2008.

Jaoui, M., Kleindienst, T. E., Lewandowski, and Edney, E. O.: Identification and quantification of aerosol polar oxygenated compounds bearing carboxylic or hydroxyl groups. 1. Method development, Anal. Chem., 76, 4765-4778, 2004.

Jaoui, M., Kleindienst, T. E., Lewandowski, M., Offenberg, J. H., and Edney, E. O.: Identification and quantification of aerosol polar oxygenated compounds bearing carboxylic or hydroxyl groups. 2. Organic tracer compounds from monoterpenes, Environ. Sci. Technol., 39, 5661-5673, 2005.

Jaoui, M., Lewandowski, M., Kleindienst, T. E., Offenberg, J. H., and Edney, E. O.: beta-caryophyllinic acid: An atmospheric tracer for beta-caryophyllene secondary organic aerosol, Geophys. Res. Lett., 34, L05816, doi:10.1029/2006GL028827, 2007.

Kautzman, K. E., Surratt, J. D., Chan, M. N., Chan, A. W. H., Hersey, S. P., Chhabra, P. S., Dalleska, N. F., Wennberg, P. O., Flagan, R. C., and Seinfeld, J. H.: Chemical composition of gasand aerosol-phase products from the photooxidation of naphthalene, J. Phys. Chem. A, 114, 913-934, 2010.

Kleindienst, T. E., Conver, T. S., McIver, C. D., and Edney, E. O.: Determination of secondary organic aerosol products from the photooxidation of toluene and their implication in $\mathrm{PM}_{2.5}$, J. Atmos. Chem., 47, 79-100, 2004.

Kleindienst, T. E., Jaoui, M., Lewandowski, M., Offenberg, J. H., Lewis, C. W., Bhave, P. V., and Edney, E. O.: Estimates of the contributions of biogenic and anthropogenic hydrocarbons to secondary organic aerosol at a southeastern US location, Atmos. Environ., 41, 8288-8300, 2007.

Kleindienst, T. E., Lewandowski, M., Offenberg, J. H., Jaoui, M., and Edney, E. O.: The formation of secondary organic aerosol from the isoprene $+\mathrm{OH}$ reaction in the absence of $\mathrm{NO}_{\mathrm{x}}$, Atmos. Chem. Phys., 9, 6541-6558, doi:10.5194/acp-9-6541-2009, 2009. 
Kleindienst, T. E., Lewandowski, M., Offenberg, J. H., Edney, E. O., Jaoui, M., Zheng, M., Ding, X., and Edgerton, E. S.: Contribution of primary and secondary sources to organic aerosol and PM2.5 at SEARCH Network Sites, J. Air Waste Manage. Assoc., 60, 1388-1399, 2010a.

Kleindienst, T. E., Lewandowski, M., Offenberg, J. H., Jaoui, M., and Docherty, K. S.: Investigations of tracers from naphthalene and its methyl analogs. Presented at the annual conference of the American Association for Aerosol Research Annual Conference, Portland, OR, 24-28 October, 2010b.

Lewandowski, M., Jaoui, M., Offenberg, J. H., Kleindienst, T. E., Edney, E. O., Sheesley, R. J., and Schauer, J. J.: Primary and secondary contribution to ambient PM in the Midwestern United States, Environ. Sci. Technol., 42, 3303-3309, 2008.

Martin-Reviejo, M. and Wirtz, K.: Is benzene a precursor for secondary organic aerosol?, Environ. Sci. Technol., 39, 1045-1054, 2005.

Nishino, N., Arey, J., and Atkinson, R.: Formation of nitro products from the gas-phase $\mathrm{OH}$ radical-initiated reactions of toluene, naphthalene, and biphenyl: Effect of $\mathrm{NO}_{2}$ concentration, Environ. Sci. Technol., 42, 9203-9209, 2008.

Nishino, N., Arey, J., and Atkinson, R.: Yields of glyoxal and ringcleavage co-products from the $\mathrm{OH}$ radical initiated reactions of naphthalene and selected alkylnaphthalenes, Environ. Sci. Technol., 43, 8554-8560, 2009a.

Nishino, N., Arey, J., and Atkinson, R.: Formation and reactions of 2-formylcinnamaldehyde in the $\mathrm{OH}$ radical-initiated reaction of naphthalene, Environ. Sci. Technol. 43, 1349-1353, 2009b.

Odum, J. R., Hoffmann, T., Bowman, F., Collins, D., Flagan, R. C., and Seinfeld, J. H.: Gas/particle partitioning and secondary organic aerosol yields, Environ. Sci. Technol., 30, 2580-2585, 1996.

Offenberg, J. H., Kleindienst, T. E., Jaoui, M., Lewandowski, M., and Edney, E. O.: Thermal properties of secondary organic aerosol, Geophys. Res. Lett., 33, L03816, doi:10.1029/2005GL024623, 2006.

Phousongphouang, P. T. and Arey, J.: Rate constants for the gasphase reactions of a series of alkylnaphthalenes with the $\mathrm{OH}$ radical, Environ. Sci. Technol., 36, 1947-1952, 2002.

Pio, C., Alves, C., and Duarte, A.: Organic components of aerosols in a forested area of central Greece, Atmos. Environ., 35, 389401, 2001.

Pun, B. K., Wu, S.-Y., Seigneur, C., Seinfeld, J. H., Griffin, R. J., and Pandis, S. N.: Uncertainties in modeling secondary organic aerosols: Three-dimensional modeling studies in Nashville/Western Tennessee, Environ. Sci. Technol., 37, 37473761, 2003.

Reisen, F. and Arey, J.: Atmospheric Reactions Influence Seasonal PAH and Nitro-PAH Concentrations in the Los Angeles Basin, Environ. Sci. Technol., 39, 64-73, 2005.
Robinson, A. L., Donahue, N. M., Shrivastava, M. K., Weitkamp, E. A., Sage, A. M., Grieshop, A. P., Lane, T. E., Pierce, J. R., and Pandis, S. N.: Rethinking organic aerosols: Semivolatile emissions and photochemical aging, Science, 315, 1259-1262, 2007.

Sasaki, J., Aschmann, S. M., Kwok, E. S. C., Atkinson, R., and Arey, J.: Products of the gas-phase $\mathrm{OH}$ and $\mathrm{NO}_{3}$ radical-initiated reactions of naphthalene, Environ. Sci. Technol., 31, 3173-3179, 1997.

Schauer, J. J., Rogge, W. F., Hildemann, L. M., Mazurek, M. A., and Cass, G. R.: Source apportionment of airborne particulate matter using organic compounds as tracers, Atmos. Environ., 30, 3837-3855, 1996.

Schauer, J. J., Kleeman, M. J., Cass, G. R., and Simoneit, B. R. T.: Measurement of emissions from air pollution sources. 2 . $\mathrm{C}_{1}$ through $\mathrm{C}_{30}$ organic compounds from medium duty diesel trucks, Environ. Sci. Technol., 33, 1578-1587, 1999.

Schauer, J. J., Fraser, M. P., Cass, G. R., and Simoneit, B. R. T., Source reconciliation of atmospheric gas-phase and particle phase pollutants during a severe photochemical smog episode, Environ. Sci. Technol., 36, 3806-3814, 2002.

Shakya, K. M. and Griffin, R. J., Secondary organic aerosol from the photooxidation of polycyclic aromatic hydrocarbons, Environ. Sci. Technol., 44, 8134-8139, 2010.

Stone, E. A., Zhou, J., Snyder, D. C., Rutter, A. P., Mieritz, M., and Schauer, J. J.: A comparison of summertime secondary organic aerosol source contributions at contrasting urban locations, Environ. Sci. Technol., 43, 3448-3454, 2009.

Szmigielski, R., Surratt, J. D., Yadian Gomez-Gonzalez, Y., Van der Veken, P., Kourtchev, I., Vermeylen, R., Blockhuys, F., Jaoui, M., Kleindienst, T. E., Lewandowski, M., Offenberg, E. O., Seinfeld, J. H., Maenhaut, W., and Claeys, M.: 3-Methyl1,2,3-butanetricarboxylic acid: An atmospheric tracer for terpene secondary organic aerosol, J. Geophys. Res., 34, L24811, doi:10.1029/2007GL031338, 2007.

Volkamer, R., San Martini, F., Molina, L. T., Salcedo, D., Jimenez, J. L., and Molina, M. J.: A missing sink for gas-phase glyoxal in Mexico City: Formation of secondary organic aerosol, Geophys. Res. Lett., 34, L19807, doi:10.1029/2007GL030752, 2007.

Wang, L., Atkinson, R., and Arey, J.: Dicarbonyl products of the $\mathrm{OH}$ radical-initiated reactions of naphthalene and the $\mathrm{C}_{1}$ - and $\mathrm{C}_{2}$ alkylnaphthalenes, Environ. Sci. Technol., 41, 2803-2810, 2007.

Washenfelder, R. A., Young, C. J., Brown, S. S., Angevine, W. M., Etlas, E. L., Blake, D. R., Bon, D. M., Cubison, M. J., de Gouw, J. A., Dusanter, S., Flynn, J., Gilman, J. B., Graus, M., Griffith, S., Grossberg, N., Hayes, P. L., Jimenez, J. L., Kuster, W. C., Lefer, B. L., Pollack, I. B., Ryerson, T. B., Stark, H., Stevens, P. S., and Trainer, M. K.: The glyoxal budget and its contribution to organic aerosol for Los Angeles, California, during CalNex 2010, J. Geophys. Res., 116, D00V02, doi:10.1029/2011JD016314, 2011. 